\title{
Design Considerations for Ceramic Matrix Composite Vanes for High Pressure Turbine Applications
}

\author{
Robert J. Boyle \\ N\&R Engineering and Management Services \\ Parma Heights, $\mathrm{OH}$ \\ Michael C. Halbig \\ NASA Glenn Research Center \\ Cleveland, $\mathrm{OH}$
}

\begin{abstract}
Issues associated with replacing conventional metallic vanes with Ceramic Matrix Composite(CMC) vanes in the first stage of the High Pressure Turbine(HPT) are explored. CMC materials have higher temperature capability than conventional HPT vanes, and less vane cooling is required. The benefits of less vane coolant are less NOx production and improved vane efficiency. Comparisons between CMC and metal vanes are made at current rotor inlet temperatures and at an vane inlet pressure of $50 \mathrm{~atm}$.. CMC materials have directionally dependent strength characteristics, and vane designs must accommodate these characteristics. The benefits of reduced NOx and improved cycle efficiency obtainable from using CMC vanes. are quantified Results are given for vane shapes made of a two dimensional CMC weave. Stress components due to thermal and pressure loads are shown for all configurations. The effects on stresses of: (1) a rib connecting vane pressure and suction surfaces; (2) variation in wall thickness; and (3) trailing edge region cooling options are discussed. The approach used to obtain vane temperature distributions is discussed. Film cooling and trailing edge ejection were required to avoid excessive vane material temperature gradients. Stresses due to temperature gradients are sometimes compressive in regions where pressure loads result in high tensile stresses.
\end{abstract}

\section{INTRODUCTION}

Ceramic Matrix Composite(CMC) vane and rotor blades can significantly improve gas turbine efficiency, due to their higher temperature capability compared to conventional metallic blades. The CMC consists of

\footnotetext{
${ }^{0}$ This material is declared a work of the U.S. Government and is not subjected to copyright protection in the United States. Approved for public release: distribution is unlimited.
}

\author{
Ankur H. Parikh \\ N\&R Engineering and Management Services \\ Parma Heights, $\mathrm{OH}$ \\ Vinod K. Nagpal \\ N\&R Engineering and Management Services \\ Parma Heights, $\mathrm{OH}$
}

Silicon Carbide( $\mathrm{SiC})$ fibers in a $\mathrm{SiC}$ matrix. Using CMC vanes in the first stage of the High Pressure Turbine(HPT) provides the greatest benefit in terms of reduced coolant and reduced NOx and $\mathrm{CO} 2$ emissions. However, vane pressure and thermal loads are also at a maximum in the first stage of the HPT. For the same rotor inlet temperature, $T_{41}, \mathrm{CMC}$ vanes require less coolant than conventional metallic vanes. While most vane coolant is non-chargeable air, in that it is available to do work in the first stage rotor, vane efficiency increases as the amount of cooling air decreases. Hartsel[1] gave a correlation to estimate the improvement in vane efficiency due to reduced coolant. Increasing vane efficiency increases cycle efficiency, and thus reduces $\mathrm{CO} 2$ emissions and fuel consumption. From a cycle standpoint reducing cooling air ejected from the vane trailing edge is even more important, since this air is generally considered chargeable air, and is unavailable to do work in the first HPT stage. When $T_{41}$ is held constant, and vane cooling air is reduced, the combustor outlet temperature, $T_{40}$, is reduced. Reducing $T_{40}$ reduces the combustor fuel-to-air ratio, and a small change in the fuel-to-air ratio has a disproportionately large change in NOx production.

CMC vanes have been designed, fabricated, and tested, as discussed by Verrilli et al.[2], Vedula et al.[3], Brewer et al.[4], Watanabe et al.[5], and Nakamura et al.[6]. Marshall and Cox[7] discussed the use of ceramic textiles in gas turbine components. These references discuss the desirability of using film cooling, since current design maximum gas temperatures exceed the expected temperature capability of the Environmental Barrier Coating(EBC) used to shield the CMC. Cycle and emissions benefits of CMCs are greatest when they are used in the first HPT stage. First stage vane pressure loads exceed those typically used in past CMC vane designs. Turbine inlet pressures are expected to ap- 
proach $50 \mathrm{~atm}$. in the near term. A film cooled vane has an internal pressure only slightly greater than the turbine inlet pressure. Much of the suction surface typically sees an external pressure about half of the turbine inlet pressure. Along much of the vane pressure surface the differential pressure across the vane wall is significantly lower than across the suction surface wall.

This work addresses the benefits and challenges associated with using CMC vanes to replace conventional metallic vanes in the high pressure turbine. The work was undertaken in consultation with Honeywell International Inc. personnel to insure that it is relevant to industry needs. All results are presented using the vane geometry given by Halila et al.[8]. It is recognized that the trailing edge thicknes of a CMC vane may need to be greater than the relatively thin trailing edge of this metal vane.

A series of cases will be examined. The first case is a vane with constant wall thickness, and a single open cavity. The second case inserts a rib connecting the suction and pressure surfaces. The third case is for a differential wall thickness, where the pressure surface is thinner than the suction surface. The fourth and fifth cases examine the consequence of using trailing edge ejection, where some of the cooling air is ejected from the vane trailing edge. Stresses due only to pressure loads, and stresses due only to temperature gradients, as well as stresses due to combined loads will be given. Stresses due to individual loads are shown because, in a specific application, loads different than those used for the analysis are likely to be applied. For example, if the inlet pressure was half of the $50 \mathrm{~atm}$. used, and the pressure distribution was similar, stresses due to pressure loads would be nearly halved. Two stress components, through thickness and hoop, will be shown. The strength of woven CMC materials in the interlaminar or through thickness direction is lower than the strength in the hoop or fiber direction.

\section{Benefits of Reduced Vane Coolant}

Property comparisons. To evaluate the benefits of CMC vanes it is necessary to choose reference properties for both the CMC material and the metal vane material. Figure 1 compares properties for the selected CMC material and for a metal, (MA754), commonly used for the first stage vane of the HPT. The properties of the CMC material(N24A), a balanced 2D weave, were obtained from Mital et al.[9]. As discussed by DiCarlo et al.[10] this is a fiber reinforced $\mathrm{SiC} / \mathrm{SiC}$ material with an upper use temperature of $1316^{\circ} \mathrm{C}\left(2400^{\circ} \mathrm{F}\right)$.

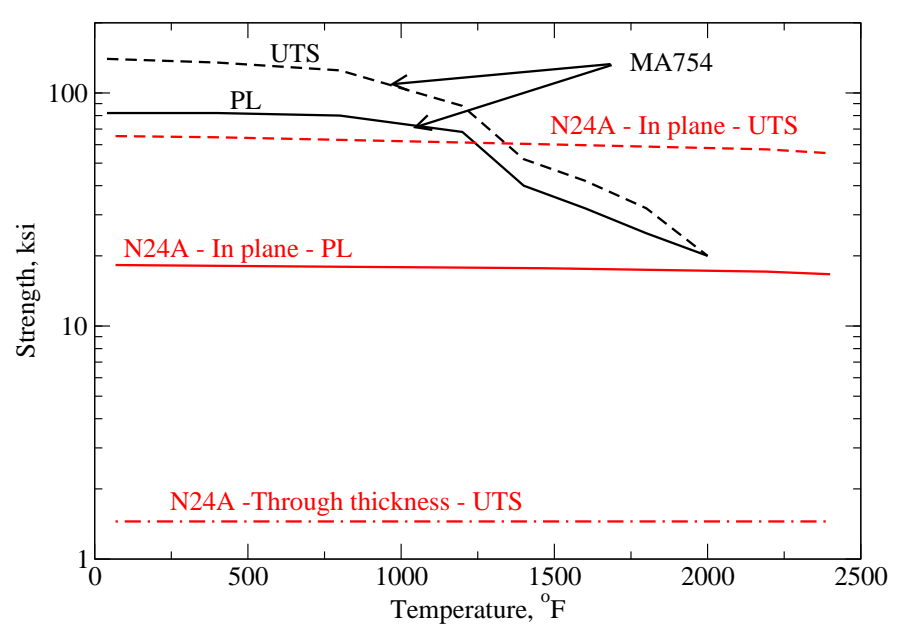

a) load capabilities

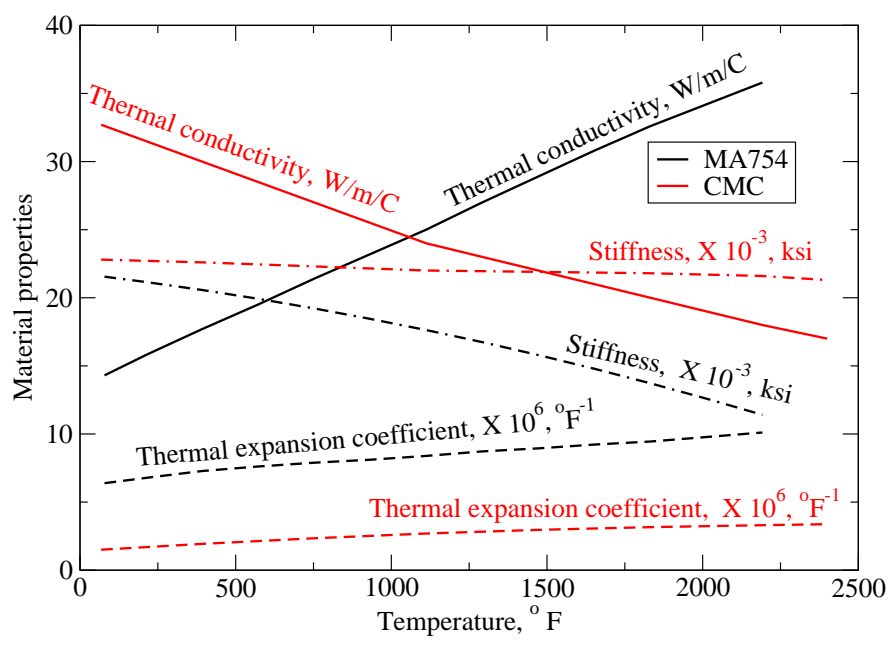

b) Material properties

Fig. 1 Comparison of metal(MA754) \& CMC(N24A) properties.

The thin EBC layer, described by Lee et al.[11], was assumed to have a temperature capability of $1483^{\circ} \mathrm{C}\left(2700^{\circ} \mathrm{F}\right)$. The MA754 properties were obtained from the Special Metals web site[12]. Figure 1a shows that the CMC material maintains its strength to a significantly higher temperature. In the plane of the weave the $\mathrm{CMC}$ has a proportional limit strength that is nearly the same as that for MA754, but MA754 has a lower maximum temperature of approximately $2000^{\circ} \mathrm{F}\left(1094^{\circ} \mathrm{C}\right)$. MA754 is an isotropic material, while the CMC has an ultimate tensile strength that is significantly lower in the through thickness direction. It will be shown that, because of the lower through thickness strength, the design of a HPT first stage vane may significantly differ from that of a metallic vane. 


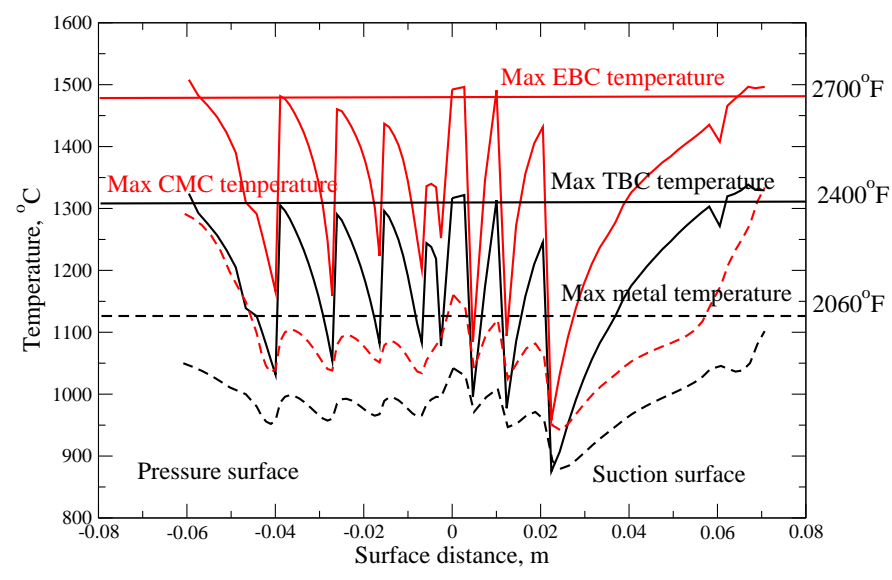

Fig. 2 Typical maximum vane and coating temperatures.

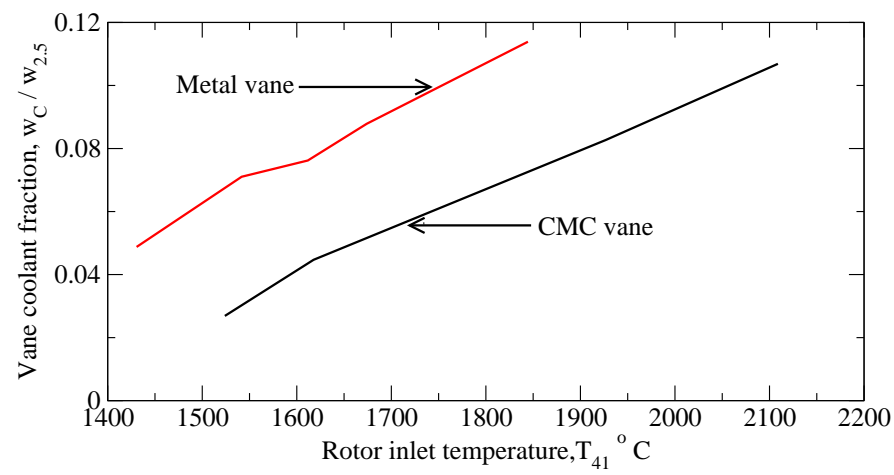

Fig. 3 Vane coolant fractions for metal and $\mathrm{CMC}$ vanes.

Figure 1b compares other properties of MA754 and the CMC material. The thermal conductivity and coefficient of thermal expansion are both lower for the CMC than for MA754. The coefficient of thermal expansion for the $\mathrm{CMC}$ material near $2000^{\circ} \mathrm{F}\left(1094^{\circ} \mathrm{C}\right)$ is nearly $3.0 \times 10^{-6}{ }^{\circ} \mathrm{F}^{-1}\left(5.4 \times 10^{-6}{ }^{\circ} \mathrm{C}^{-1}\right)$. In terms of thermal stresses these properties are somewhat offsetting. A lower thermal conductivity increases thermal gradients, but a lower coefficient of thermal expansion reduces stresses for a given thermal gradient. The CMC stiffness shown is in the plane of the weave, and the interlaminar stiffness was $60 \%$ of the value shown in figure $1 b$.

Figure 2 shows typical maximum temperatures for the CMC and the protective low conductivity EBC layer. These temperatures are the midspan outer temperatures of each layer. A surface distance of zero corresponding to the leading edge stagnation point. Since CMC materials require an EBC, comparisons were made assuming that both the metal and CMC vanes had prime reliant $0.25 \mathrm{~mm}(10 \mathrm{mil})$ Thermal Barrier Coatings(TBC). A relatively thick $\mathrm{EBC}$ or TBC layer, reduces the temperature gradients in the vane walls. The desirability of reducing the wall temperature gradient will be shown.
The calculations shown in figure 2 were done using data from Reiss and Bolcs[13] for the leading edge region film effectiveness and heat transfer, and the correlation developed by Boyle and Ameri[14] for film cooling effectiveness. Local film cooling effectiveness was calculated assuming superposition from upstream cooling rows. The outer temperatures show a saw tooth pattern, and temperature minimums indicate the location of film cooling rows. No suction surface film cooling rows were downstream of the vane throat, since doing so causes excessive aerodynamic losses. The relatively thick barrier coatings resulted in the outer coatings reaching their maximum temperatures, while most of the vane temperatures were less than their maximum values. Using a thick barrier coating lessened the vane through thickness temperature gradients, which lowered vane thermal stresses.

Figure 3 shows calculated vane coolant fractions, (vane coolant-to-compressor discharge, $\left(w_{\mathrm{C}} / w_{2.5}\right)$ ratio) for both the metal and CMC vanes. Comparisons at constant rotor inlet temperature, $T_{41}$, show that the reduction in vane coolant when using $\mathrm{CMC}$ vanes is nearly independent of $T_{41}$. The calculated coolant fractions included both film cooling and cooling using trailing edge ejection. The portion of the cooling air fraction attributable to trailing edge ejection was found using internal heat transfer correlations and appropriate pressure losses.

NOx reduction from CMC vanes. NOx is reduced by reducing the combustor outlet temperature, $T_{40}$. A constant specific heat energy balance shows that:

$$
T_{40}=T_{41}\left(1+w_{\mathrm{C}} / w_{40}\right)-w_{\mathrm{C}} / w_{40} T_{3}
$$

where $T_{3}$ is both the compressor discharge and coolant temperature, and $w_{\mathrm{C}} / w_{40}$ is the coolant-to-combustor discharge flow rate ratio. $w_{\mathrm{C}} / w_{40}$ is slightly greater than $w_{\mathrm{C}} / w_{2.5}$, the coolant to compressor discharge ratio.

The fuel-to-air ratio, $(f / a)$, is proportional to the combustor temperature rise, $T_{40}-T_{3}$. Tacina et al. $[15,16]$ correlated NOx production as a function of $f / a$, and showed that, depending on the combustor design, the exponent on $f / a$ can range as high as 5.57. Figure 4a shows the percentage reduction in NOx for various correlations. For exponents greater than 4 , a $5 \%$ reduction in coolant results in more than a $20 \%$ reduction in NOx. Figure 4b shows that low exponents on $f / a$ are not associated with low absolute NOx levels.

Cycle benefits of CMC vanes Improved thermodynamic efficiency has a direct benefit in terms of fuel burn, and therefore $\mathrm{CO} 2$ emissions. Cycle efficiency is improved when vane coolant is reduced. While the 


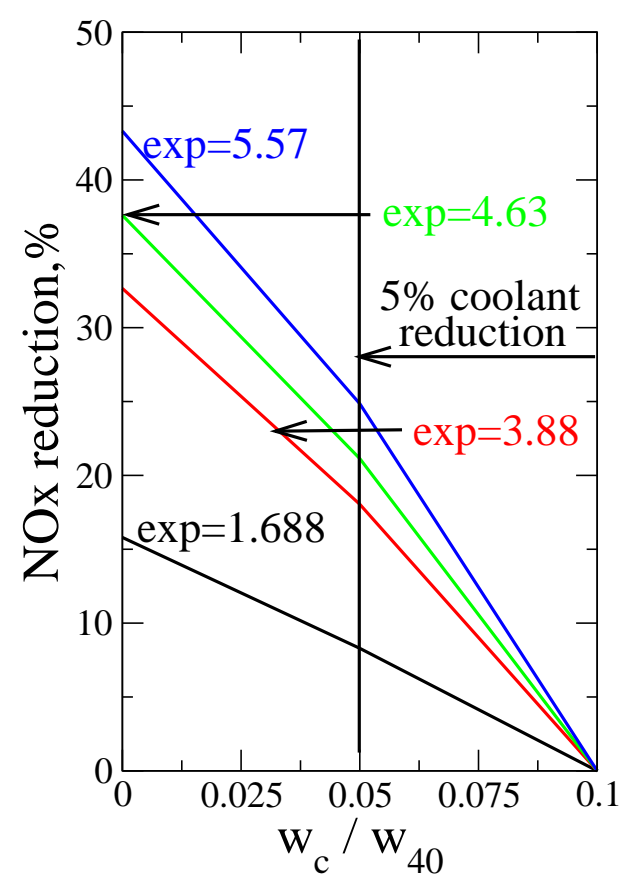

a) Relative NOx change

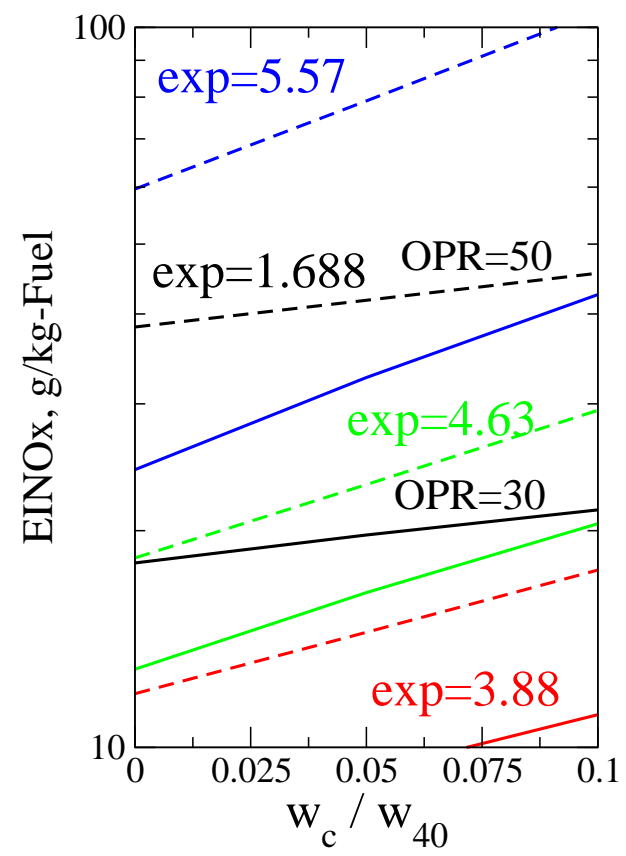

b) Typical NOx production rate

Fig. 4 Sensitivity of NOx to vane coolant ratio.

maximum reduction in Specific Fuel Consumption(SFC) is achieved when both the vane and rotor blades are CMCs, rotor blades are subject to additional stresses. The primary focus of this effort is the SFC improvement from the reduction in vane coolant. The evaluations are done assuming $T_{41}$ is held constant.
Most first stage HPT vane coolant is considered to be non-chargeable air. However, air that is injected into the mainstream flow downstream of the vane throat is chargeable air, and is unavailable to do work in the HPT first stage rotor. Calculations showed that replacing metallic vanes with $\mathrm{CMC}$ vanes reduces chargeable air used for vane cooling by $1.2 \%$ of compressor discharge air. Since the HPT drives the compressor, this $1.2 \%$ reduction in HPT first stage vane chargeable air improves SFC by $0.6 \%$ for a highly efficient two stage HPT with equal work splits, and an equal work split between the HPT and Low Pressure Turbine.

Figure 3 shows that the vane coolant decreased by nearly $5.5 \%$ of compressor discharge air, $w_{2.5}$. According to Hartsel[1] and others, reductions in cooling flow reduce the vane pressure loss, since there is a mixing loss when the vane coolant mixes with the mainstream air. Calculations using the correlation given by Hartsel[1] showed that the $5.5 \%$ reduction in vane coolant air increased the total pressure at the rotor inlet by $0.86 \%$. Even though this increase in total pressure is less than $1 \%$, the small increase in turbine output of $0.2 \%$ contributes to an increase in cycle efficiency of approximately $0.4 \%$. Reducing both trailing edge cooling and overall cooling for the first stage vane of the HPT results in the cycle efficiency improving nearly $1 \%$.

If using CMC material reduces first stage HPT coolant requirements, cooling can be eliminated for the second stage HPT vane. This also improves SFC. In the design report of reference 8 , the second stage HPT vane cooling flow was $1.85 \%$, of which $0.75 \%$ was used for purge air. It is conservative to assume a $1.1 \%$ reduction in stage two vane cooling air due to using CMC vanes. While second stage air is chargeable air, it may come from an intermediate compressor stage, and thus is not fully chargeable air. On the other hand, according to Honeywell International Inc. personnel, in small engine applications, it is sometimes desirable to extract HPT cooling air for both stages from the compressor exit. A $1.1 \%$ reduction in second stage HPT vane cooling air improves cycle efficiency by $0.55 \%$, when this air is compressor discharge air. It is estimated that the SFC improvement would be about $0.3 \%$ when second stage vane cooling air is extracted from and intermediate compressor stage. The Hartsel[1] correlation gives only a small reduction in second stage vane pressure loss due to the elimination of cooling air.

The maximum SFC improvement is achieved by maintaining the cooling fraction and raising the rotor inlet temperature, $T_{41}$. Without penalizing the rotor for additional cooling air, raising $T_{41}$ implicitly assumes both $\mathrm{CMC}$ vanes and rotors. Figure 5 shows cycle efficiency for a representative set of conditions, and the 


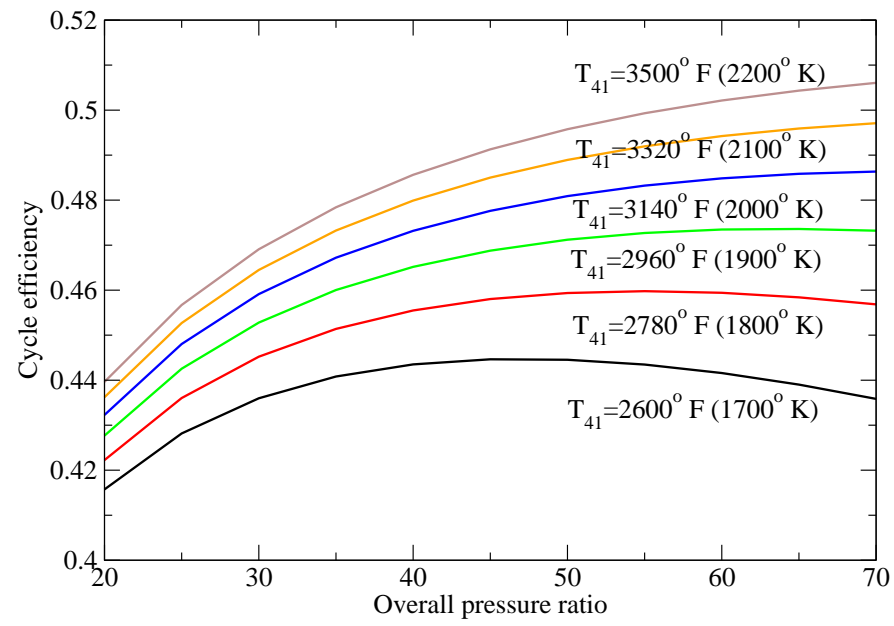

Fig. 5 Typical cycle efficiency, constant coolant fraction

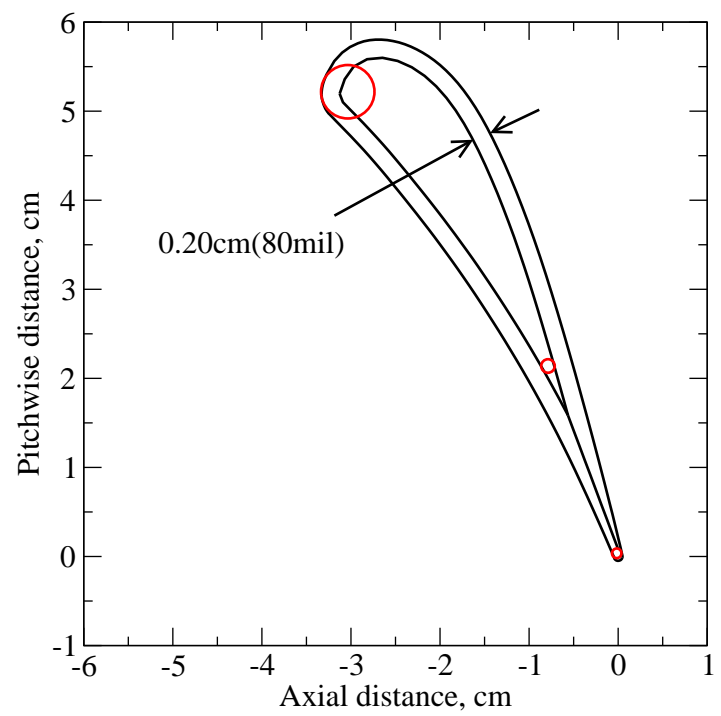

Fig. 6 Reference vane geometry

assumption that rotor cooling flow fractions are independent of temperature. Higher gas temperatures are achieved by improving the temperature capability of the vane and rotor materials. In reference 17 , it was shown that there is no improvement in cycle efficiency with increasing temperature for an ideal cycle, due to the specific heat increasing with temperature. However, this is not the case when stage efficiencies are less than one. At the lowest $T_{41}$, efficiency decreases for Overall Pressure Ratio(OPR) beyond 45, but efficiency continues to increase with OPR for higher temperatures.

Analyses were also done for the increase in $T_{41}$ when using $\mathrm{CMC}$ vanes. Maximum surface temperatures were $2700^{\circ} \mathrm{F}\left(1756^{\circ} \mathrm{K}\right)$ for the $\mathrm{CMC}$ vane and $2400^{\circ} \mathrm{F}\left(1589^{\circ} \mathrm{K}\right)$ for the metal vane. The vane coolant fraction was held constant at $10.6 \%$ of compressor discharge air. Coolant air temperature was also held constant. The rotor inlet temperature for the metallic vane was calculated to be $2935^{\circ} \mathrm{F}\left(1886^{\circ} \mathrm{K}\right)$. Somewhat surprisingly, the increase in $T_{41}$ was greater than the $300^{\circ} \mathrm{F}\left(167^{\circ} \mathrm{C}\right)$ increase in the maximum surface tem-
Table I. Description of cases analyzed

\begin{tabular}{|c|c|c|c|c|c|}
\hline \multirow{2}{*}{ Case } & \multicolumn{2}{|c|}{ Rib } & Wall & CMC & $\begin{array}{c}\text { T.E. } \\
\text { Ejection }\end{array}$ \\
\cline { 2 - 3 } & Present & Insulated & Thickness & $\Delta T$ & No \\
\hline 1 & No & - & Uniform & Uniform & No \\
$1 \mathrm{a}$ & No & - & Uniform & Non-Uniform & No \\
2 & Yes & No & Uniform & Non-Uniform & No \\
3 & Yes & No & Differential & Non-Uniform & No \\
$3 \mathrm{a}$ & Yes & Yes & Differential & Non-Uniform & No \\
4 & Yes & Yes & Differential & Non-Uniform & Yes \\
5 & Yes & Yes & Differential & Non-Uniform & Yes \\
\hline
\end{tabular}

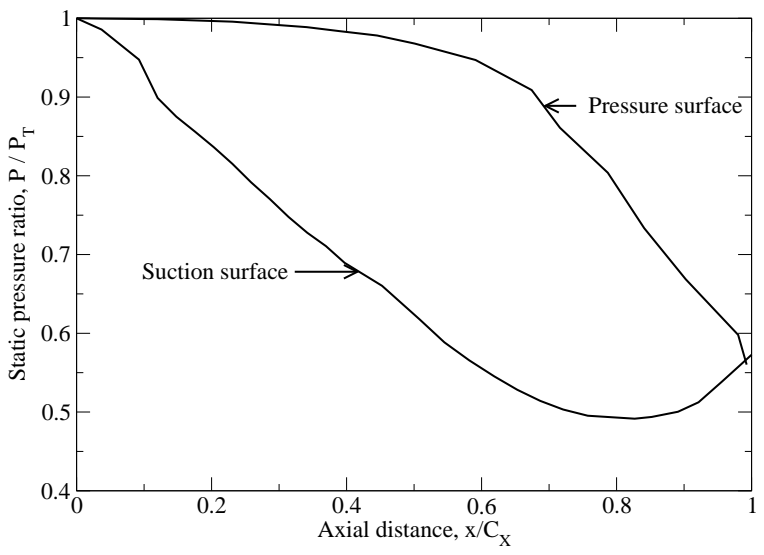

Fig. 7 External pressure distribution

peraturer. $T_{41}$ increased by $525^{\circ} \mathrm{F}\left(292^{\circ} \mathrm{C}\right)$ when the metallic vane was replaced by a CMC vane.

\section{Stress Analysis of CMC Vanes}

Table I summarizes the five geometric variations which were analyzed. Case 1a differed from case 1, and case 3 a differed from case 3 in that the CMC temperatures were different between the pairs of cases. Case 1 had no rib connecting the pressure and suction surfaces. Case 2 had uninsulated ribs connecting the pressure and suction surfaces. Case 3 had a thinner pressure surface wall than was used in cases 1 and 2 . The suction surface wall thickness was not changed throughout the analysis. Case 4 showed the effects of having trailing edge ejection to control CMC temperatures. Case 5 had the trailing edge ejection tube exiting the vane on the pressure surface, rather than on vane chamber line. For all cases, except the first, film cooling was used, However, the total cooling fraction was significantly higher without trailing edge ejection.

Figure 6 shows the vane used for the analysis. The external vane shape is for the EEE vane of Halia et al.[8]. Three red circles are shown in this figure. The largest circle shows the leading edge region curvature. While the actual leading edge is elliptical in shape, the leading edge radius is approximately $0.3 \mathrm{~cm}(118 \mathrm{mil})$. The thickness of the suction surface was always $0.20 \mathrm{~cm}(80 \mathrm{mil})$, The effects of reducing the thickness of the pressure surface from this value will be 


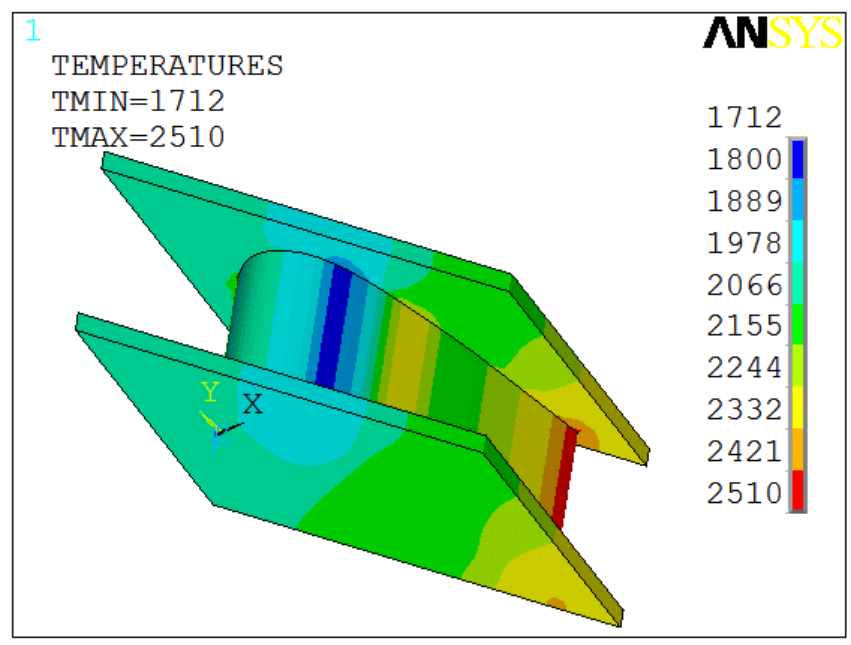

Fig. 8 Vane with two endplates

discussed. A smaller circle of $0.076 \mathrm{~cm}(30 \mathrm{mil})$ radius is shown where the inner CMC surfaces come together. Stress analysis for uniform wall thickness cases were done assuming this radius where the inner suction and pressure walls join to form the fork region. The third circle with a radius of $0.0535 \mathrm{~cm}(21 \mathrm{mil})$ is at the trailing edge. The analysis was done using this radius, even though a thicker trailing edge is likely to be needed for a CMC vane.

Throughout the analysis the same external pressure distribution was used, and it is shown in figure 7 . This figure shows the local external static-to-inlet total pressure ratio as a function of axial distance. While the pressure differential across much of the suction surface is nearly half of the inlet total pressure, the differential across the pressure surface is much less. Inside the vane, the gas pressure was assumed equal to the inlet total pressure, and this pressure was 50 atm.

Because of the non-uniform strength characteristics of CMC materials, directionally dependent stresses were calculated. Figure 8 shows the geometry analyzed, which consisted of a vane with two end plates. The edges of one end plate were fixed, and the other end plate was free to move in the spanwise or radial direction. While both end plates have the same dimensions, this arrangement accurately represents a typical vane installation. Three stress components were calculated, but only the through thickness and hoop components will be discussed in detail. The through thickness stresses are in directions normal to the inner surfaces, including the rib surfaces. In the solid trailing edge region, where there is no inner surface, the through thickness direction is normal to the outer surface. The hoop stresses are normal to the through thickness stresses, and are in the same spanwise plane. All stress analysis was done using the ANSYS computer program[18]. Because component stresses will be shown, stresses were

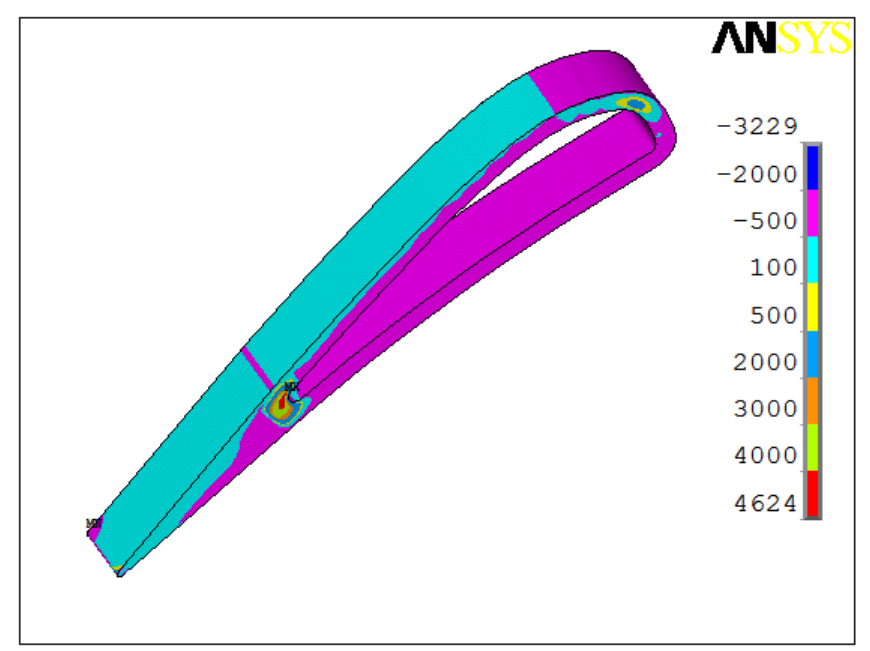

a) Through thickness stress, psi

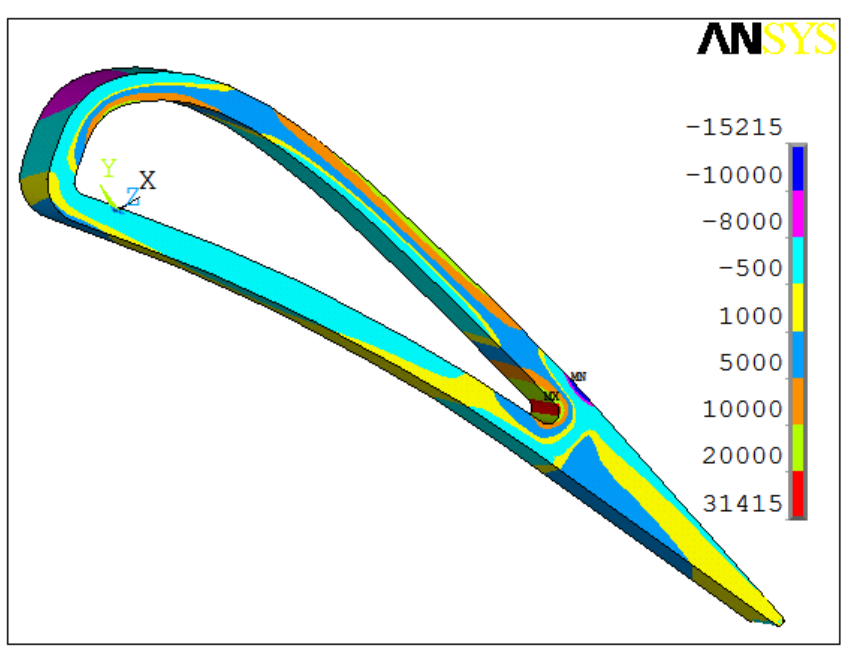

b) Hoop stress, psi

Fig. 9 Case 1 component stresses due to pressure uniform wall thickness

determined using the ANSYS "as calculated" option. This option yielded stresses in the local coordinate systems. A summary table of maximum component stresses in through thickness, hoop, and spanwise directions is given after all cases have been discussed.

Uniform wall thickness and no connecting rib. A primary reason for undertaking the stress analysis is to identify useful approaches to mitigating peak stresses in future CMC vane designs. Therefore, stresses due to pressure and thermal loads are shown separately. Both loads are present in an actual engine operation. Stress distributions with both loads present are shown in order to see the interaction due to these loads. A somewhat arbitrary goal of this work was to have through thickness stresses below $10.3 \mathrm{MPa}(1.5 \mathrm{ksi})$ and hoop stresses below $117 \mathrm{MPa}(17 \mathrm{ksi})$, which were based on the structural capability of the N24A material. 


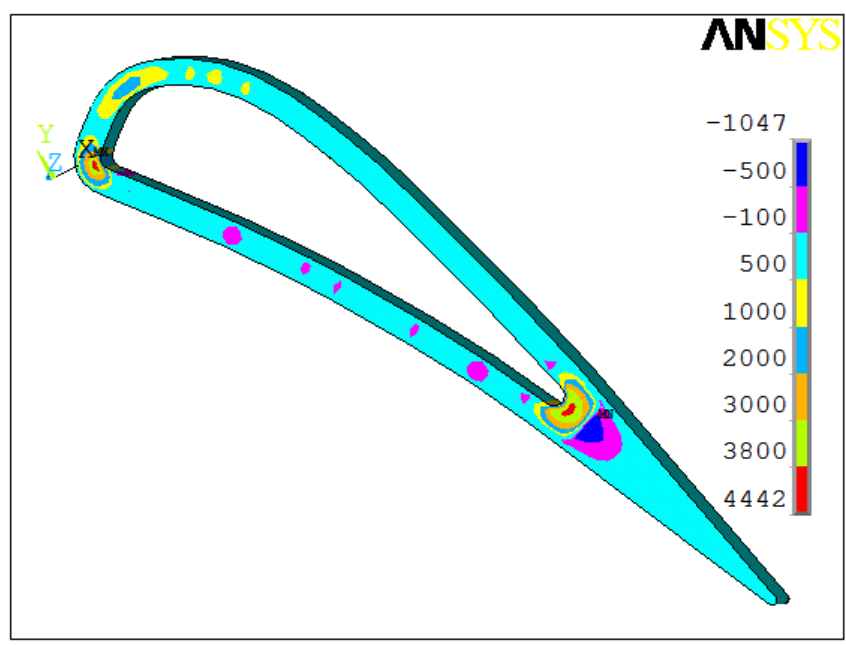

a) Through thickness stress, psi

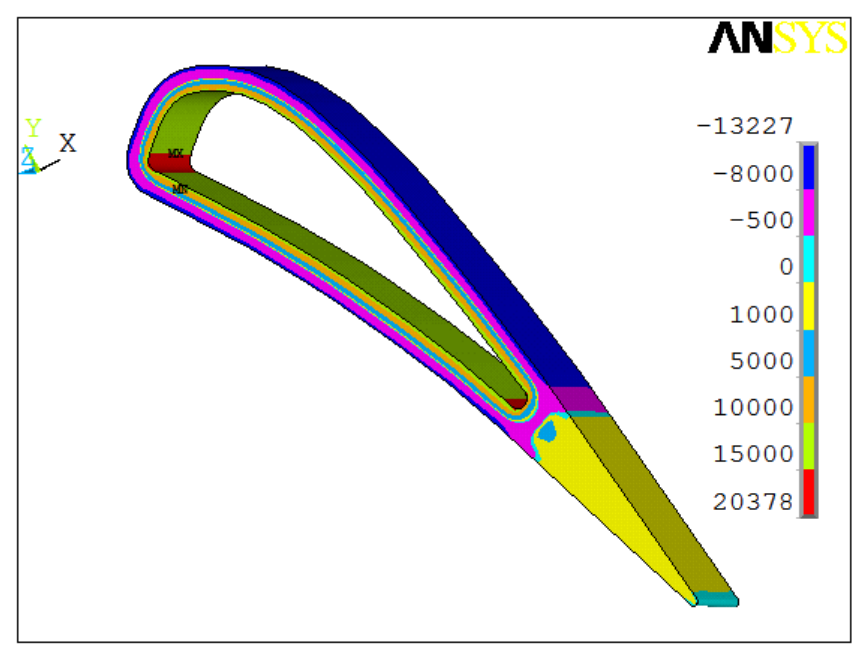

b) Hoop stress, psi

Fig. 10 Case 1 component stresses from uniform $\Delta T$ uniform wall thickness

Figure 9 shows through thickness and hoop stresses due to pressure loads. The portion of the vane near midspan is shown in these figures. While high through thickness stresses are confined to a very small region just aft of where the suction and pressure surface meet, the maximum stress is excessive. The maximum hoop stress occurs on the inner surface at the rear of the hollow vane, and towards the suction surface, which is near the same location as the maximum through thickness stress. High hoop stresses occur only in a small region, but exceed the goal of $117 \mathrm{MPa}(17 \mathrm{ksi})$.

Figure 10 shows the same two stress components when only a temperature load is applied. For reference purposes a uniform temperature was applied to the exterior and interior surfaces. The vane exterior wall was $83^{\circ} \mathrm{C}\left(150^{\circ} \mathrm{F}\right)$ hotter than the interior wall. The most striking feature of this case is that for both through

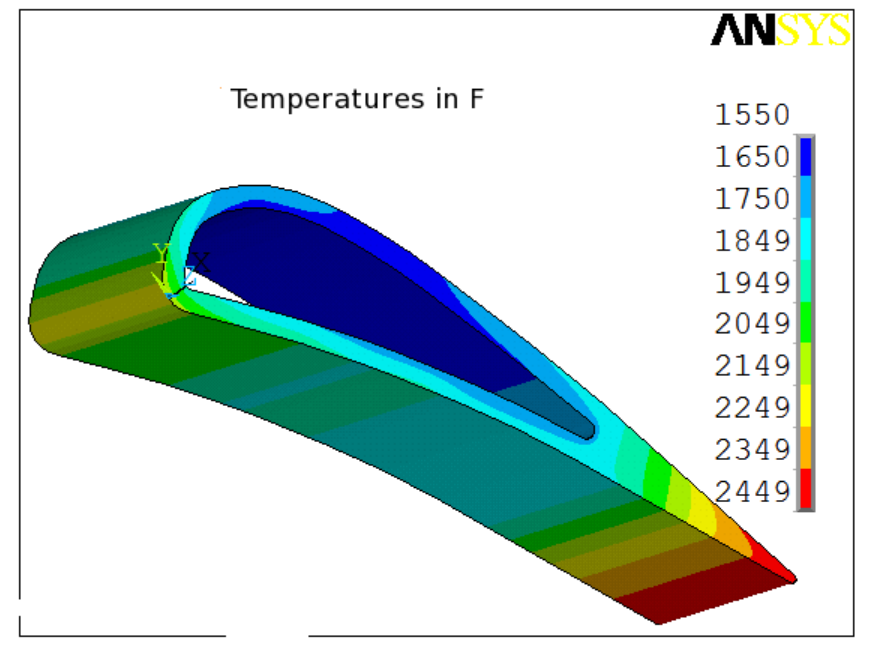

Fig. 11 Temperature distribution for non-uniform $\Delta T$

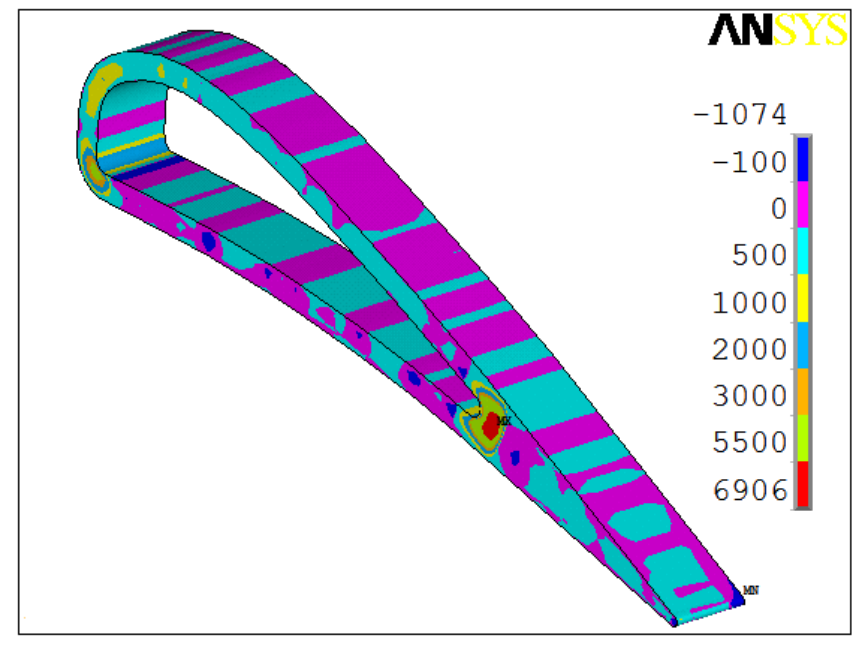

a) Through thickness stress, psi

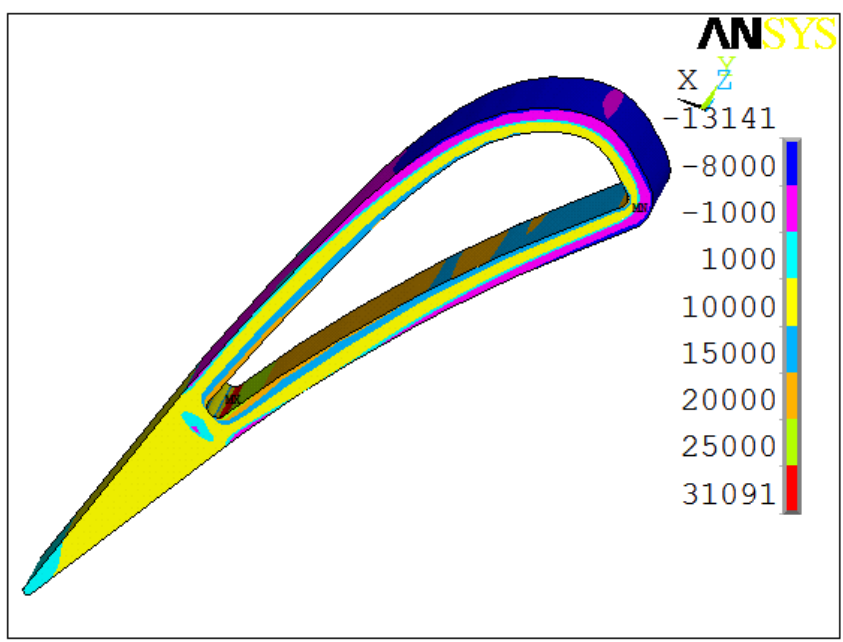

b) Hoop stress, psi

Fig. 12 Case 1a component stresses from non-uniform $\Delta T$ - uniform wall thickness 
thickness and hoop stresses regions of high and low stresses are very close together. For the through thickness stress, this occurs in the fork region, where pressure and suction surfaces join. For the hoop stress, high stresses are seen on the inner wall at the aft end of the cavity, and low stresses are seen just aft of this location.

Figure 11 shows a non-uniform temperature distribution for the vane. There are very low temperatures on the suction surface just upstream of the vane throat. These temperatures are very low because a large amount of coolant was required to film cool the suction side of the trailing edge region, in the absence of trailing edge ejection. Because of aerodynamic efficiency considerations, film cooling rows were not used on the suction surface downstream of the throat. The uniform differential temperature across the vane wall is unlikely in actual turbine applications, since a uniform temperature difference is inconsistent with film cooling. The temperature distribution shown in figure 11 is not likely to be present in an actual application. Without trailing edge ejection cooling, excessive film cooling is required, which nearly negates the advantage of a CMC vane compared with a metal vane. However, these distributions are very useful for illustrating the effects of temperature gradients on vane stresses.

Figure 12 shows similar results to those in figure 10 , but with non-uniform temperatures on both the exterior and interior surfaces. The non-uniform temperatures were determined from an analysis that included the effects of film cooling rows. Just downstream of the film cooling row, where the film effectiveness is high, the exterior and interior temperatures reach a local minimum. The stresses shown here do not include a stress concentration factor. High stresses are very localized, and in a specific application film cooling rows can be located where stress concentrations will not result in excessive stresses. While the general shape of the through thickness stress distribution is similar to that shown in figure 10a for a uniform $\Delta T$, peak tensile stresses are nearly $50 \%$ higher. Peak hoop stresses are also nearly $50 \%$ higher for the non-uniform temperature case. Figure 12a shows that the region behind the aft cavity has the maximum tensile stress close to where the through thickness stresses are compressive. The analysis given by Kaufman[19] for a metal vane showed that, as a result of creep, peak tensile stresses are likely to be lower than are calculated by the analysis used for the current work. The proportional reduction in peak stress is unlikely to be the same for a $\mathrm{CMC}$ and metal vane. On a relative basis the ranking of different configurations is expected to be the same when the analysis includes creep effects. The nearly $50 \%$ higher maximum stresses for the non-uniformal temperature case shows the desirability of using multiple rows of minimum diameter film cooling holes.

Figure 13 shows that combining pressure and temperature loads results in very high peak stresses. While

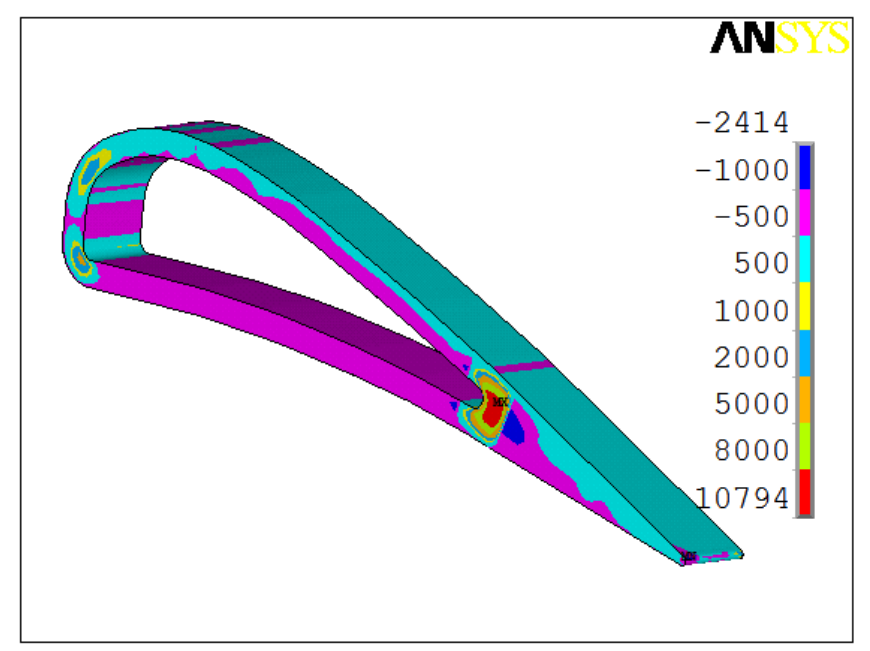

a) Through thickness stress, psi

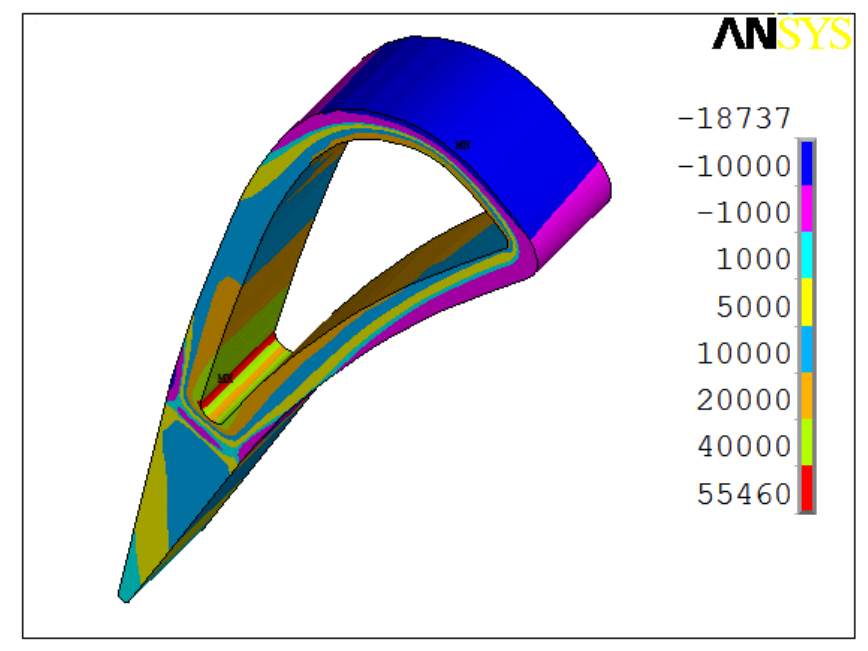

b) Hoop stress, psi

Fig. 13 Case 1a component stresses from non-uniform $\Delta T$ and pressure - uniform wall thickness

the peak through thickness stress is nearly six times the goal for maximum through thickness stress, most of the vane shows lower stresses than the goal of $10.3 \mathrm{MPa}(1.5$ $\mathrm{ksi})$. The peak hoop stress is nearly three times greater than the goal of $117 \mathrm{MPa}(17 \mathrm{ksi})$. Fortunately, excessive hoop stresses are confined to a relatively small region of the vane.

Uniform wall thickness and connecting rib. Figures 14 to 16 give component stresses when a rib joins the pressure and suction surfaces. Stresses were determined for several rib locations, and these results are for a rib location which significantly reduced pressure stresses, and still left sufficient room in the rear cavity for an impingement insert. Comparing figures 9 and 14 shows that the rib reduced maximum through thickness stresses due to pressure loads by nearly a factor of 8 three. With a rib the maximum hoop stress was nearly 


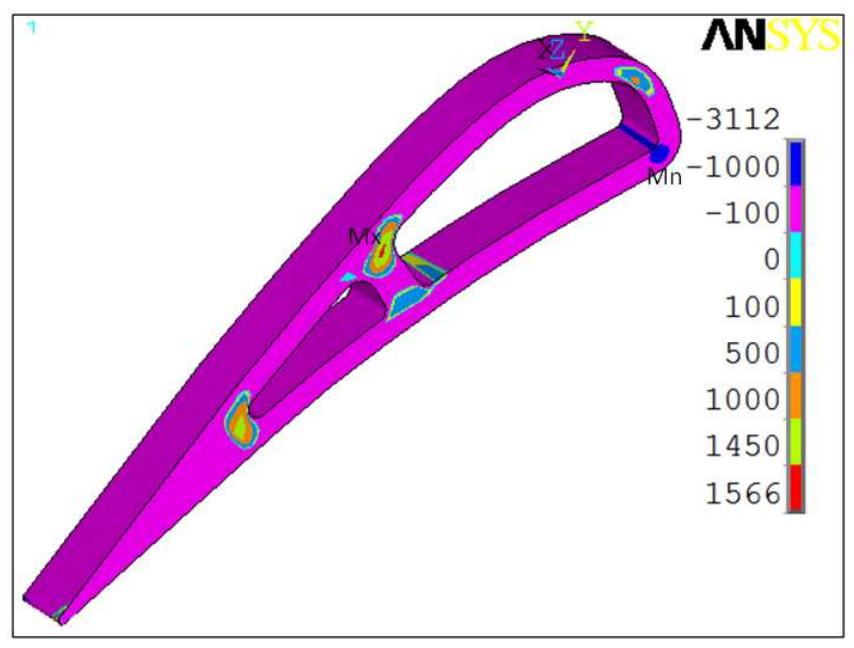

a) Through thickness stress, psi

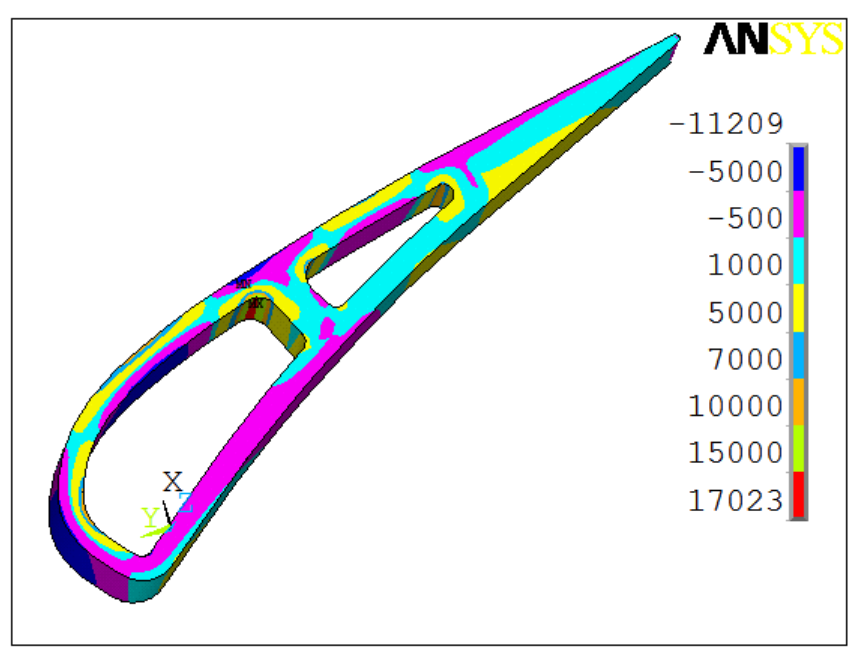

b) Hoop stress, psi

Fig. 14 Case 2 stresses for ribbed vane- pressure only uniform wall thickness

halved, and perhaps more significantly the maximum hoop stress in the fork region was reduced by nearly a factor of five.

Comparing figures 12 and 15 shows the undesirable effect that maximum thermal stresses increase when a rib is present. In the fork region, where the both through thickness and hoop stresses were highest for the no rib case(figure 12), stresses remained about the same. The maximum thermal stresses occurred in the rib-pressure surface junction region. This maximum was nearly $30 \%$ greater than the maximum thermal stress without a rib, which occurred in the fork region. The temperature distribution was calculated assuming that the rib was cooled just like the rest of the vane internal surface. The effect of insulating the rib, and thereby affecting the local temperature distribution, will be examined for a subsequent case.

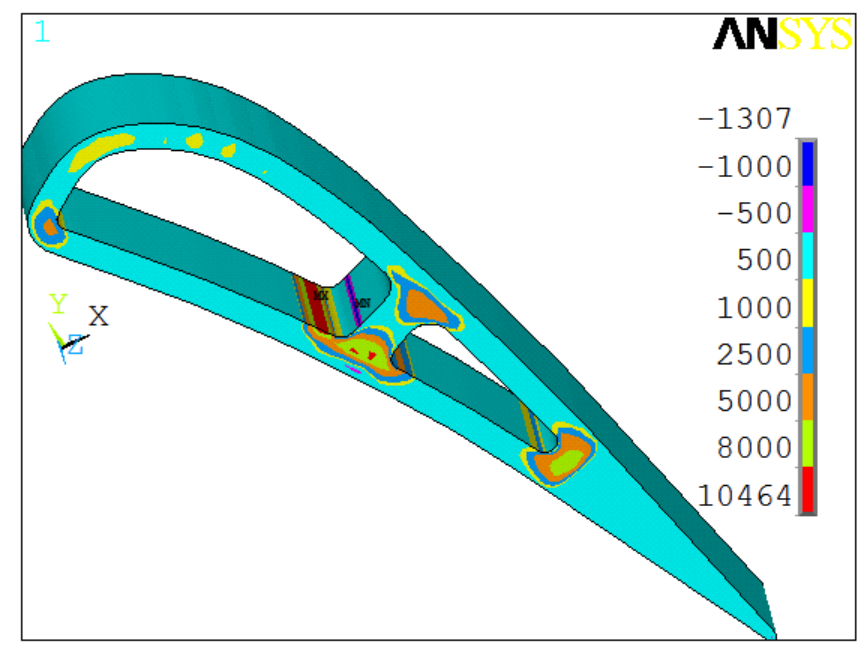

a) Through thickness stress, psi

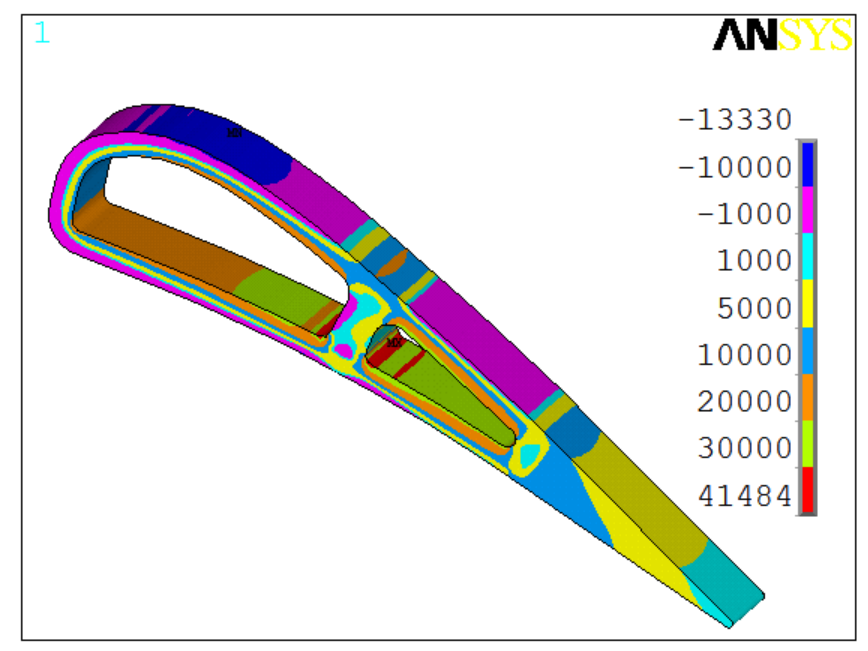

b) Hoop stress, psi

Fig. 15 Case 2 stresses for ribbed vane - non-uniform $\Delta T \&$ no pressure - uniform wall thickness

Comparing figures 15 and 16 shows that adding pressure loads to temperature loads has a very small effect on either the maximum through thickness or the maximum hoop stress.

Figure 16a shows that much of the pressure and suction surfaces have relatively low through thickness stresses. Film cooling holes cause local stress concentrations. Film cooling holes could be inserted over most of the vane surface without exceeding through thickness stress limits. Unfortunately, this is not the case for hoop stresses, as it is seen in figure 16b that much of the inner pressure surface has stesses in excess of of 20ksi(138MPa). Since film cooling holes have a pitch in the spanwise direction of three or less, the minimum area to resist hoop stresses is reduced by a third or more. Even without additional stress concentrations, 


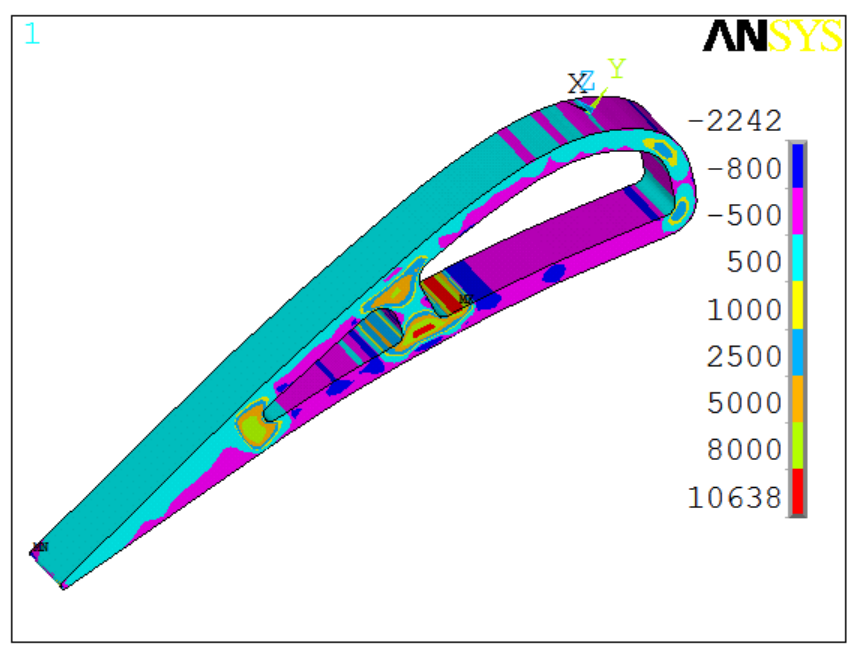

a) Through thickness stress, psi

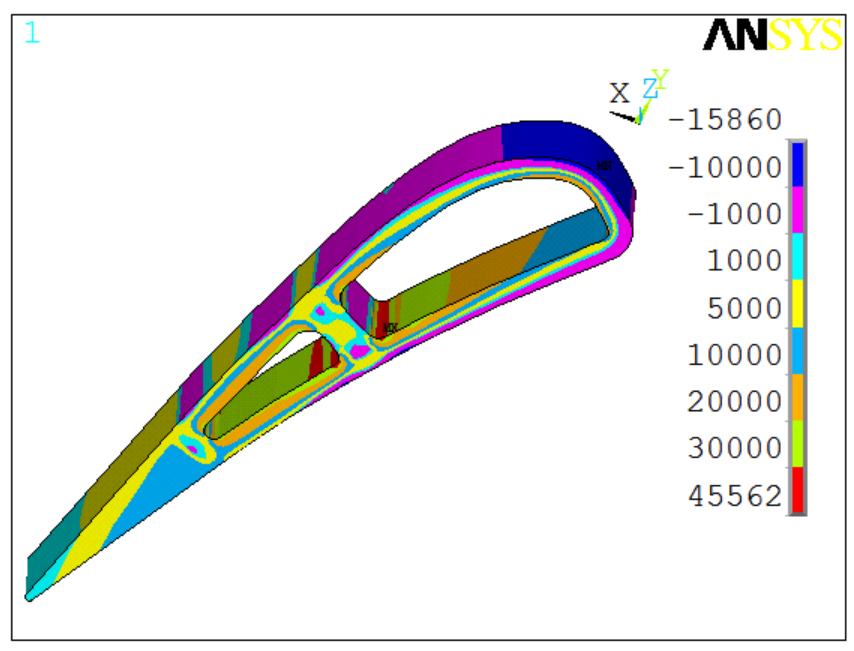

b) Hoop stress, psi

Fig. 16 Case 2 stresses for ribbed vane - non-uniform $\Delta T$ with pressure - uniform wall thickness

the area reduction is likely to result in excessive stresses near film cooling hole rows. Spanwise stresses are less affected by film cooling holes, since the film cooling rows are further apart.

Differential wall thickness and connecting rib. Figure 17 shows stresses due to pressure loads for a differential wall thickness case. The rib location is unchanged from the uniform wall thickness case. The pressure surface and leading edge region wall thickness was reduced to $1 \mathrm{~mm}(40 \mathrm{mil})$, half that of the suction surface. Decreasing the suction surface below $2 \mathrm{~mm}$ ( $80 \mathrm{mil})$ caused a very rapid increase in already high maximum stresses.

Comparing figures 14 and 17 shows that the differential wall thickness had varying effects on through thickness pressure stresses. The maximum through thickness stress increased where the rib joins the suction

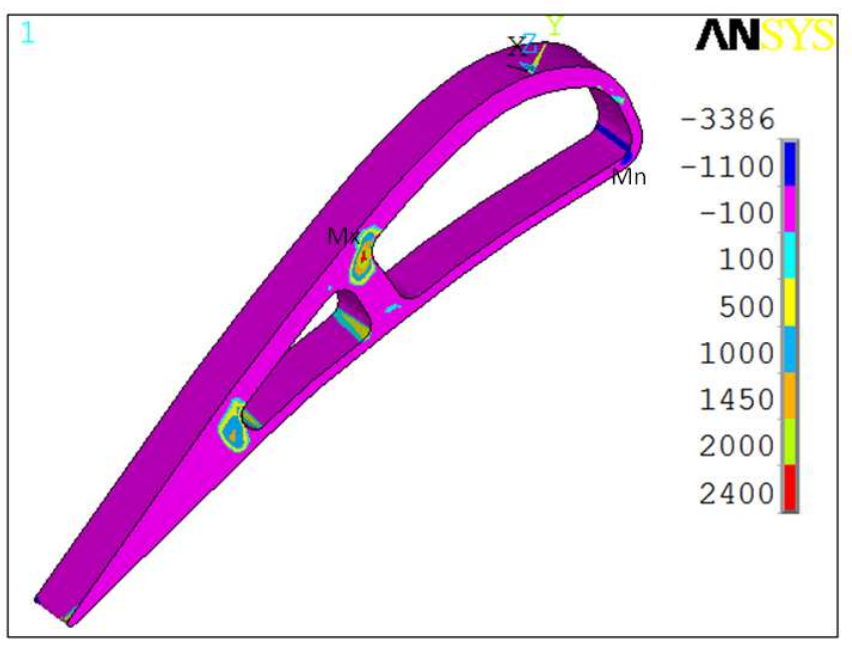

a) Through thickness stress, psi

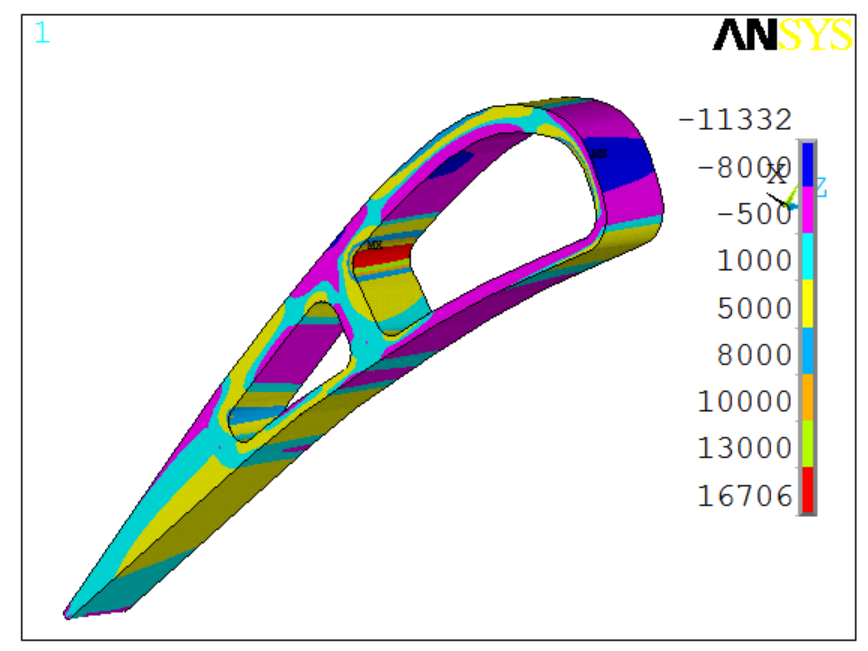

b) Hoop stress, psi

Fig. 17 Case 3 stresses for ribbed vane - pressure only - differential wall thickness

surface, but decreased in the fork region. With the decrease in the pressure surface wall thickness the radius at the rear of the aft cavity increased substantially, which resulted in lower stresses. The relative changes in maximum hoop stress due to a thinner wall were less than the changes in maximum through thickness stress.

Two assumptions were made regarding heat transfer from the rib, and these assumptions lead to significantly different stresses in the rib region. The first assumption was that the rib was cooled, just like the rest of the internal vane surface, by impingement cooling. The other assumption was that the rib was insulated. Figure 18 shows the temperature distributions for these two assumptions. Figures 19 and 20 show thermal stresses for each of these assumptions regarding heat transfer from the rib. 


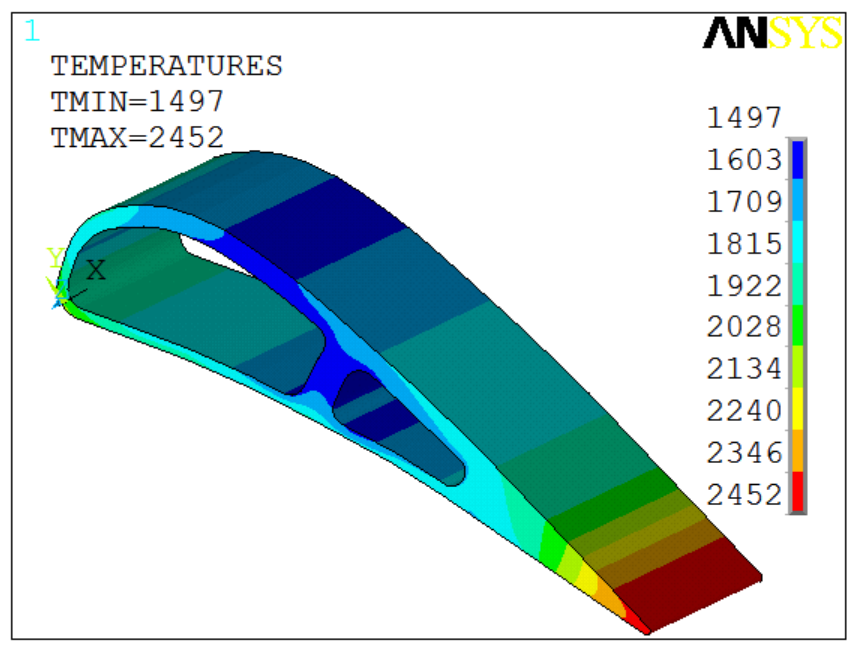

a) Temperatures for a cooled rib, ${ }^{\circ} F$

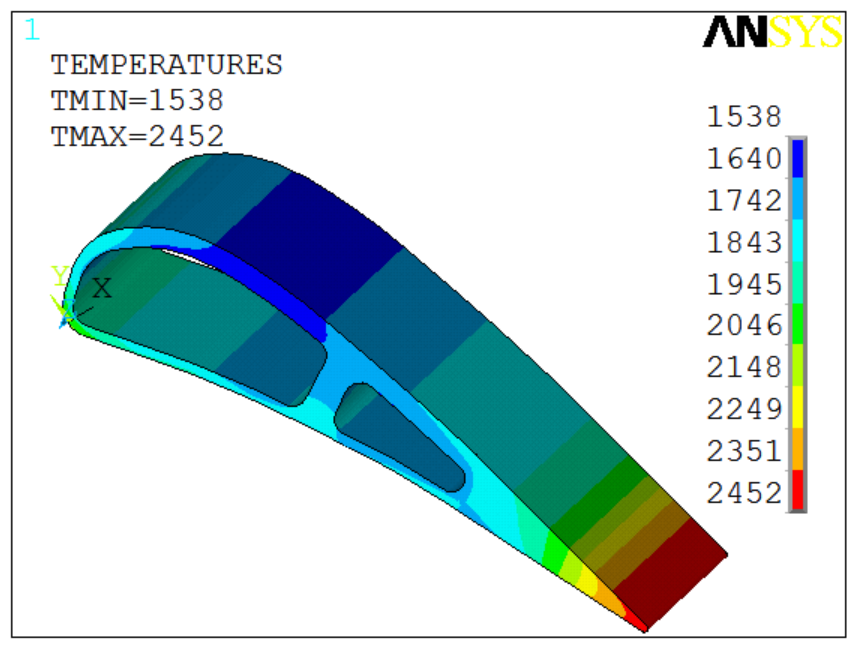

b) Temperatures for an insulted rib, ${ }^{\circ} F$

Fig. 18 Temperature distributions for two rib heat transfer assumptions

Comparing figures 15 and 19 shows that stresses due to thermal loads are less when a differential wall thickness is used. In contrast to the results for pressure loads, the through thickness stresses are significantly lower for the differential wall thickness case. These stresses are reduced in the rib wall junction area, as well as in the fork region. Hoop stresses are less affected by having a differential wall thickness.

The results in figure 19 are for a rib that is cooled by impingement cooling in the same manner as the rest of the vane internal surface. Figure 20 gives stresses when the rib is insulated. This can be achieved just by having a solid surface on the side of the impingement inserts that face the rib. Insulating the rib substantially reduces maximum through thickness and hoop stresses. Not surprisingly, the reduction in maximum through thickness stress occurs in the rib region. The peak hoop

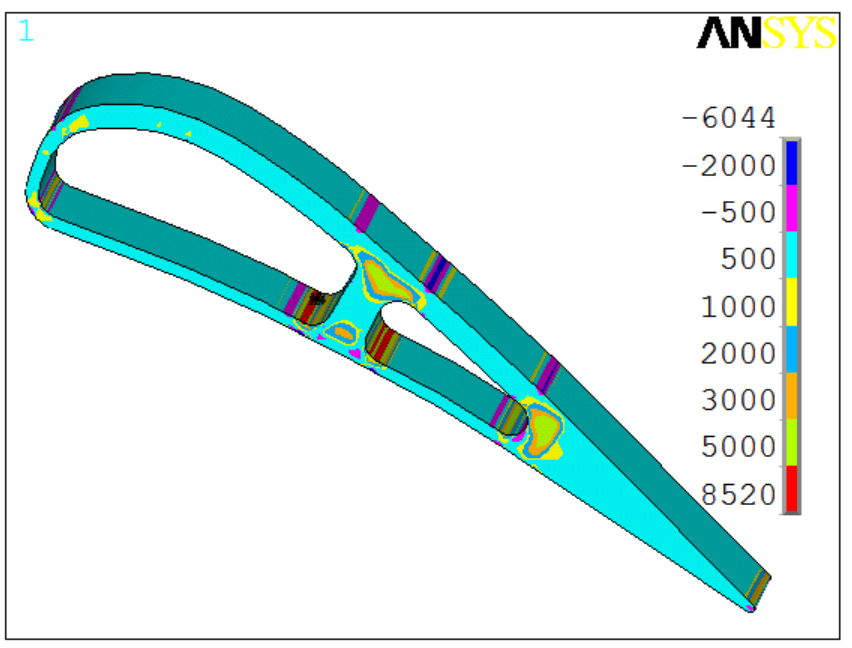

a) Through thickness stress, psi

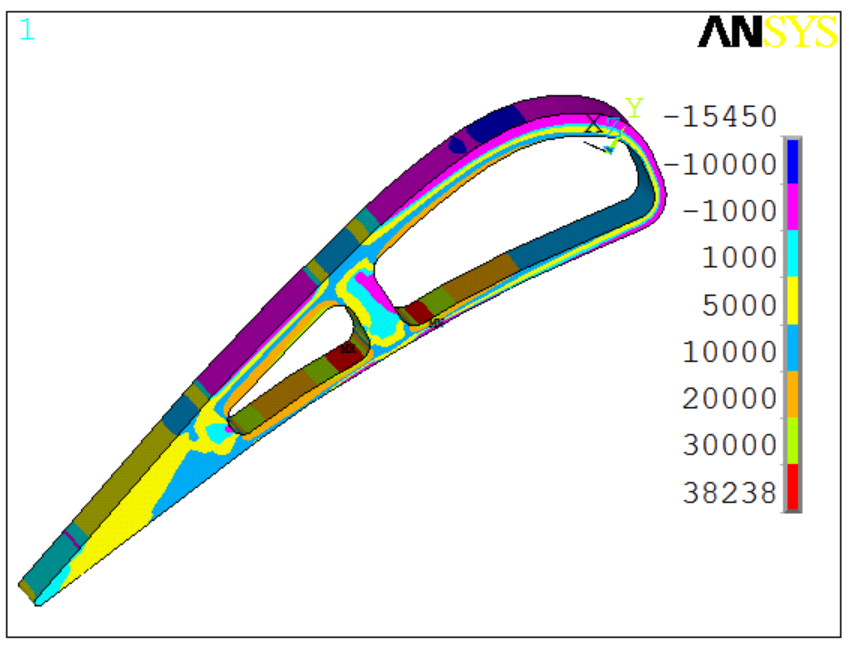

b) Hoop stress, psi

Fig. 19 Case 3 stresses for cooled rib - non-uniform $\Delta T$ - no pressure - differential wall thickness

stress moves from the rib region to the fork region, and in the process decreases by nearly $20 \%$.

Figure 21 shows stresses when both thermal and pressure loads are applied. There is an increase in maximum through thickness stress of nearly $10 \%$. The increase in maximum hoops stress when pressure loads are added to thermal loads is nearly $20 \%$. The rib configuration was not optimized. It is expected that a revised rib geometry, such as a rib with larger radii at the wall junctions, would result in lower peak stresses.

Trailing edge ejection. Figures 22 through 25 show stresses for a case with trailing edge ejection. As can be seen from figure 22 this vane consists of alternate layers of a solid region behind the rear cooling cavity, and a layer with a converging passage between the rear cavity and the trailing edge. The passage converges only in 


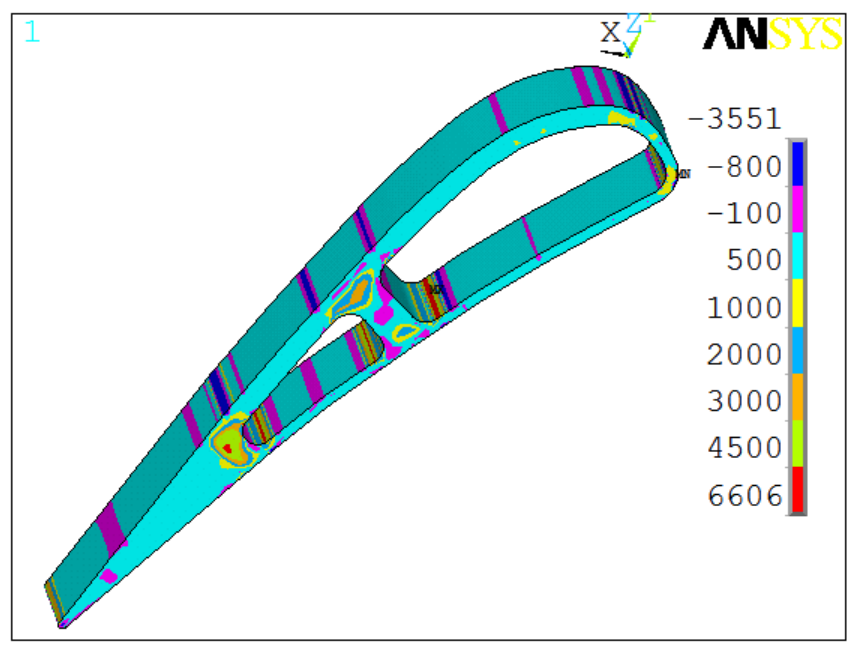

a) Through thickness stress, psi

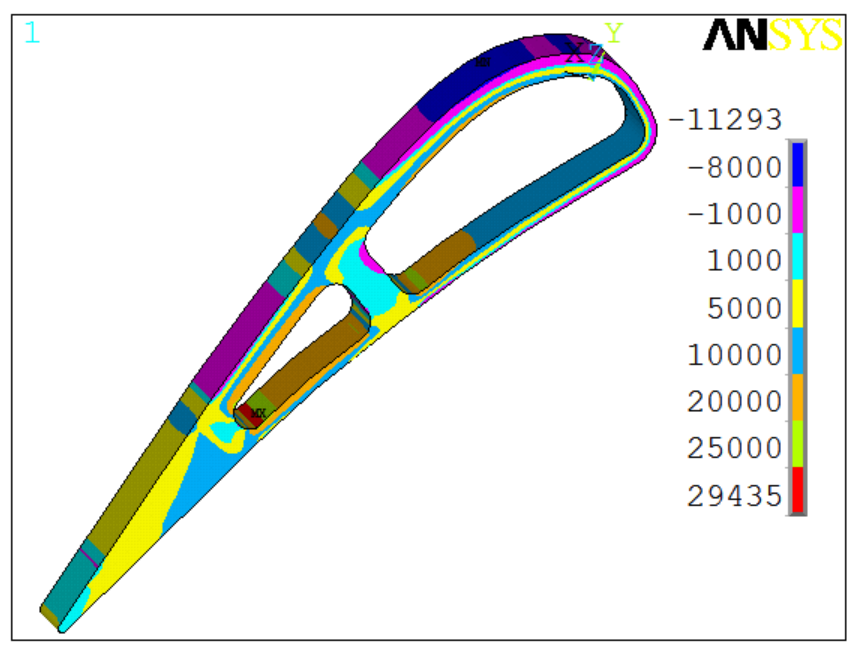

b) Hoop stress, psi

Fig. 20 Case 3a stresses for insulated rib - non-uniform $\Delta T$ - no pressure - differential wall thickness

the pitchwise direction. The passage height is constant in the spanwise direction. There were 10 holes, each with a height of $0.86 \mathrm{~mm}(34 \mathrm{mil})$ in the spanwise direction. The spanwise pitch between holes was $3.05 \mathrm{~mm}(120 \mathrm{mil})$, so that $73 \%$ of the pitch was solid. Verrilli et al.[2] showed a fabricated vane with cooling holes at the rear of the pressure surface. This configuration had features similar to a trailing edge ejection configuration.

Comparing figures 17 and 22 shows that, as expected, stress levels significantly change only aft of the rear cavity. Through thickness stresses, shown in figure $17 \mathrm{a}$ are less than $16.5 \mathrm{MPa}(2.4 \mathrm{ksi})$ for the solid trailing edge. Figure 22a shows similar stresses at the rib location. However, the maximum stress is $62.1 \mathrm{MPa}(9.0 \mathrm{ksi})$ near the junction of the trailing edge passage and the passage wall. The maximum and minimum through

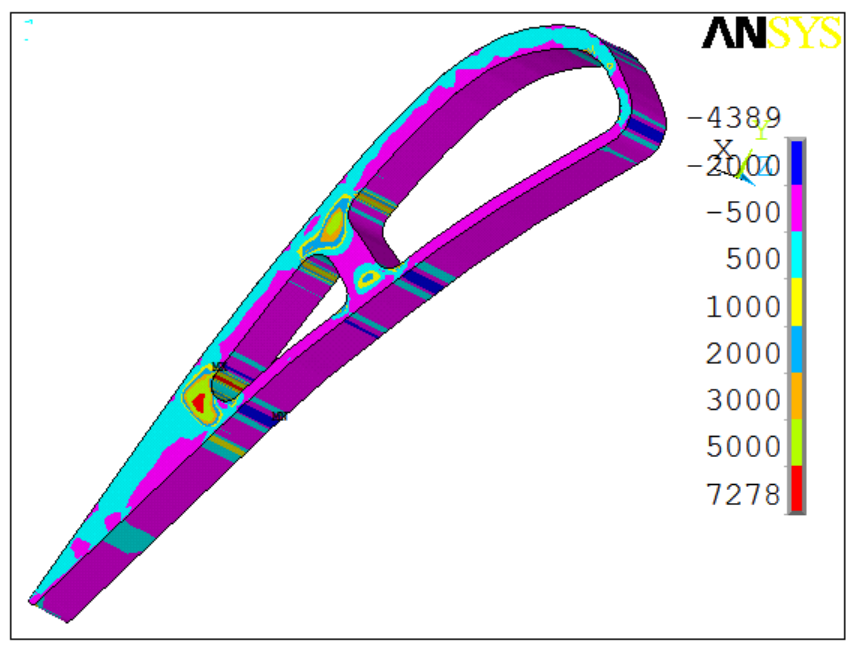

a) Through thickness stress, psi

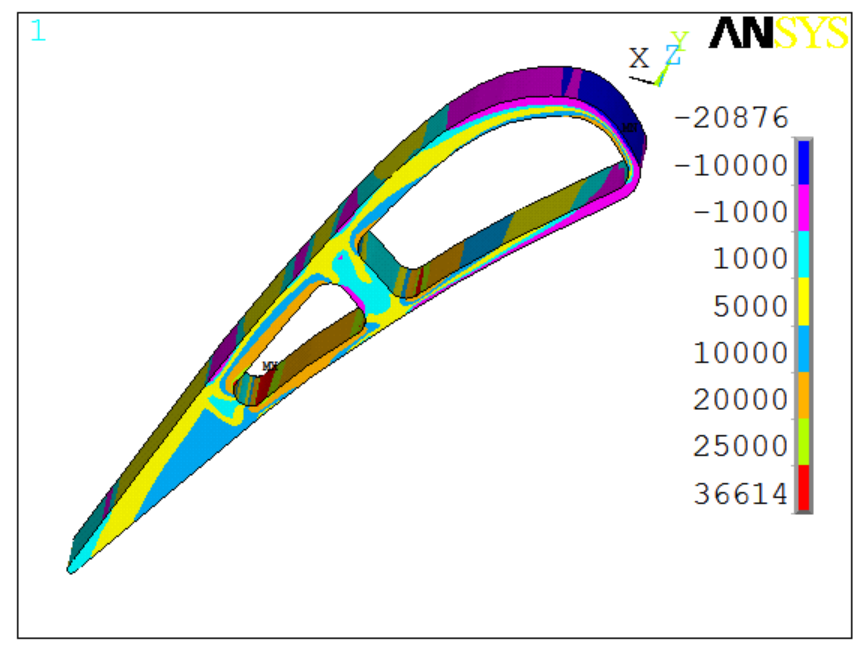

b) Hoop stress, psi

Fig. 21 Case 3a stresses for insulated rib - non-uniform $\Delta T$ - with pressure - differential wall thickness

thickness stresses occur close to each other, on opposite sides of the passage wall. For the remainder of the passage, through thickness stresses are either compressive or low tensile stresses. Hoop stresses are only slightly affected by having a trailing edge slot. The region of higher hoop stresses is confined to a very small region near the junction of the rear cavity and the suction surface passage side wall.

Figure 23 shows the temperature distribution for the vane with trailing edge ejection. Compared with figure $18 \mathrm{~b}$ suction surface temperatures before the rib are much warmer. This is because less film coolant was needed with trailing edge ejection. Figure 23 shows the coolest temperatures near the inlet of the trailingedge-ejection(TEJ) tube. A constant heat transfer coefficient of $9122 \mathrm{~W} / \mathrm{m}^{2 \circ} \mathrm{K}$, and a gas temperature of $1497^{\circ} \mathrm{F}\left(1087^{\circ} \mathrm{K}\right)$ were used in the TEJ. 


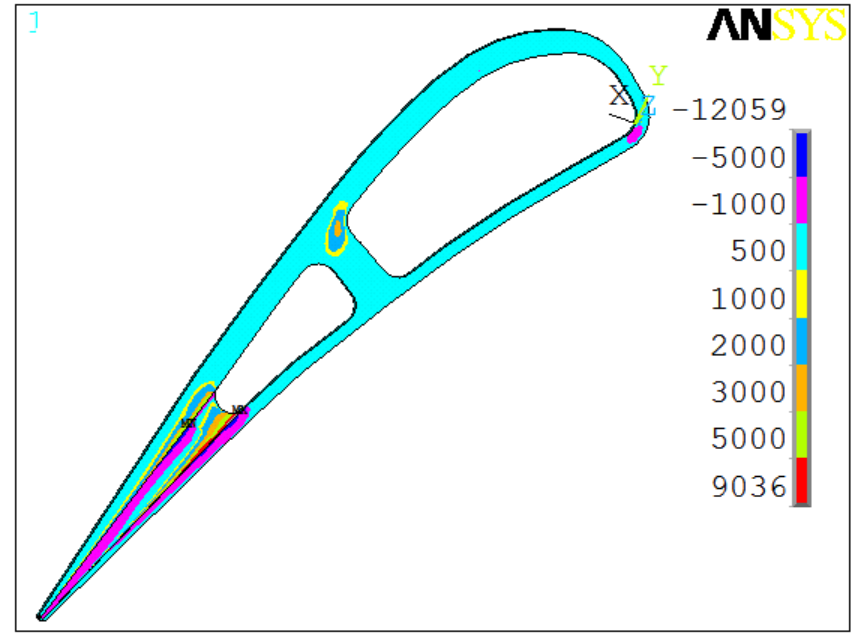

a) Through thickness stress, psi

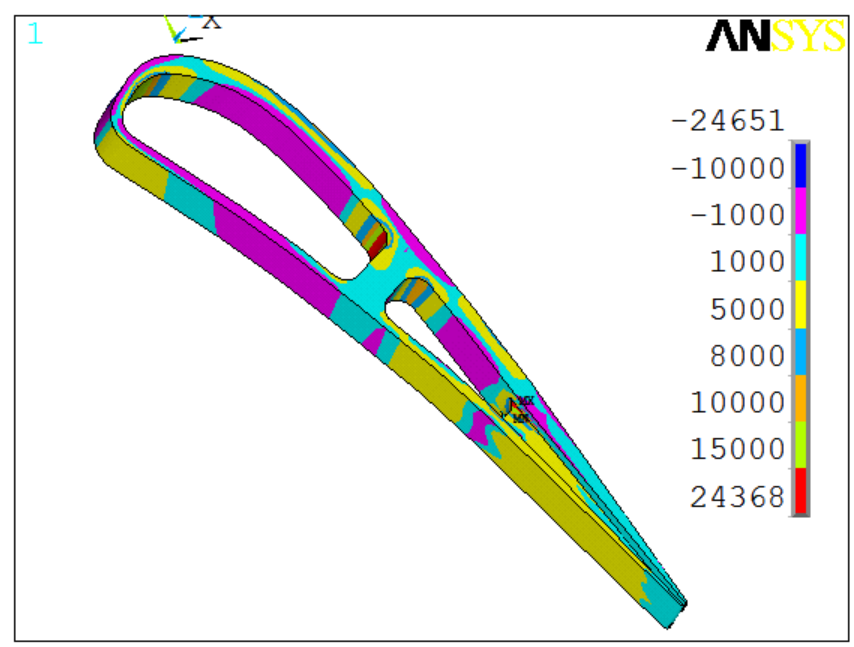

b) Hoop stress, psi

Fig. 22 Case 4 stresses for vane with trailing edge ejection - pressure only - differential wall thickness

Figure 24 shows stresses due to the temperature distribution shown in figure 23. Through thickness stresses are excessive towards the end of the TEJ tube. Peak hoop stresses are very localized, and occur near the front of the TEJ tube. This is an area where there were high stresses even without trailing edge ejection, and a significant amount of material has been removed for the tube.

Comparing figures 22 and 24, with figure 25 shows that maximum through thickness stresses do not increase when pressure and temperature loads are combined. However, hoop stresses significantly increase when both loads are combined.

Figure 26 shows that halving the heat transfer coefficient in the TEJ tube substantially reduces peak through thickness stresses. However, halving the tube heat transfer coefficient, which lowers the vane temperature gradients does not lower hoop stresses in the region of the TEJ tube. The tube heat transfer

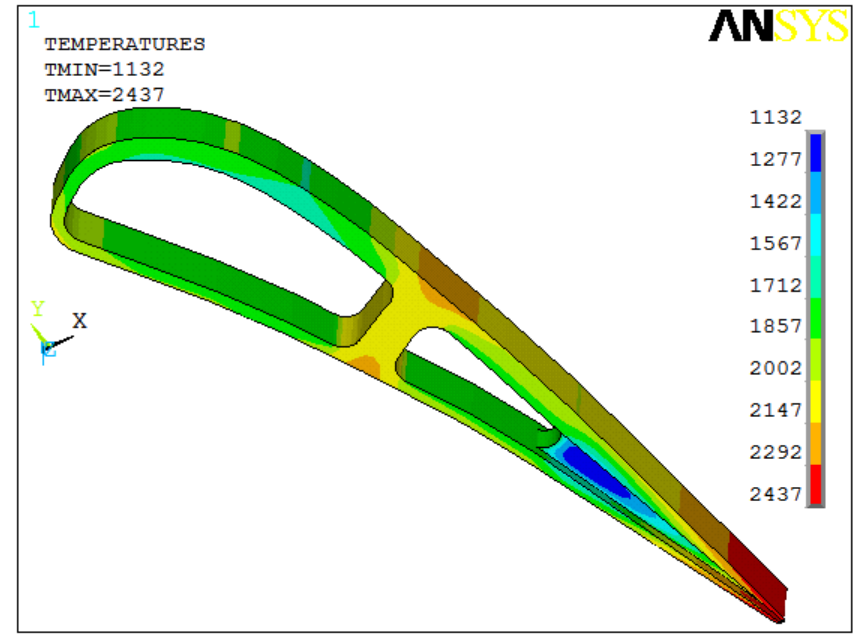

Fig. 23 Temperature distributions for vane with trailing edge ejection

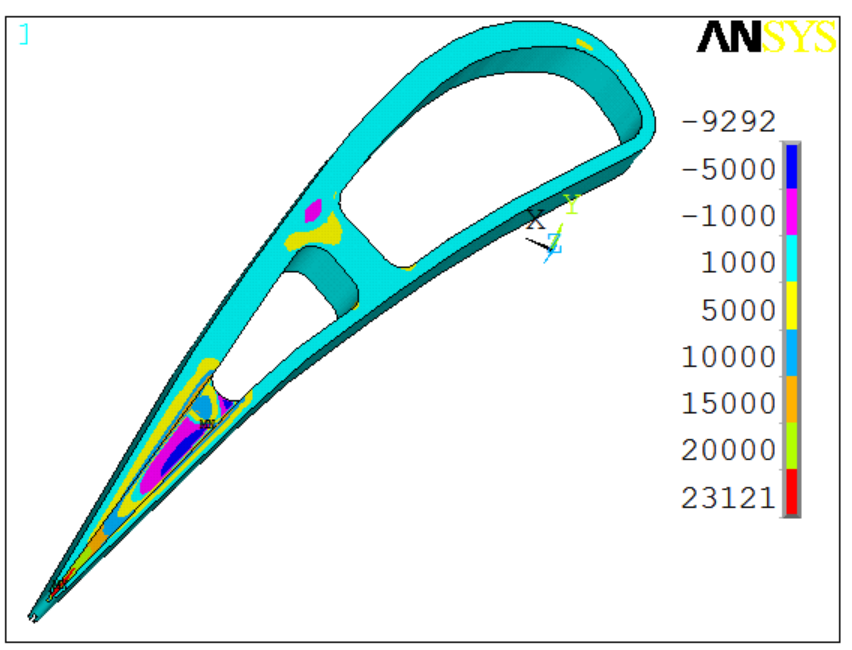

a) Through thickness stress, psi

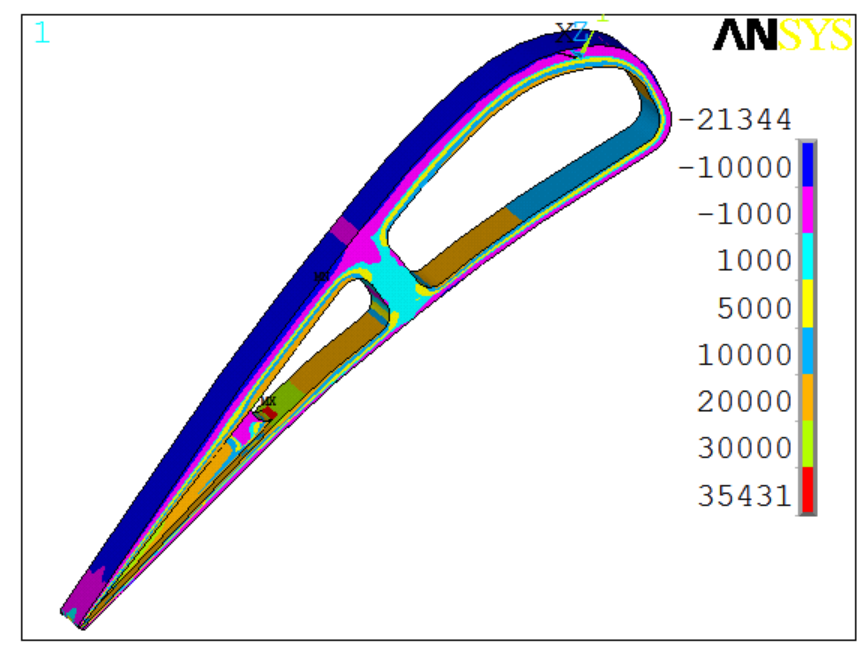

b) Hoop stress, psi

Fig. 24 Case 4 stresses for vane with trailing edge ejection - temperature only - differential wall thickness 


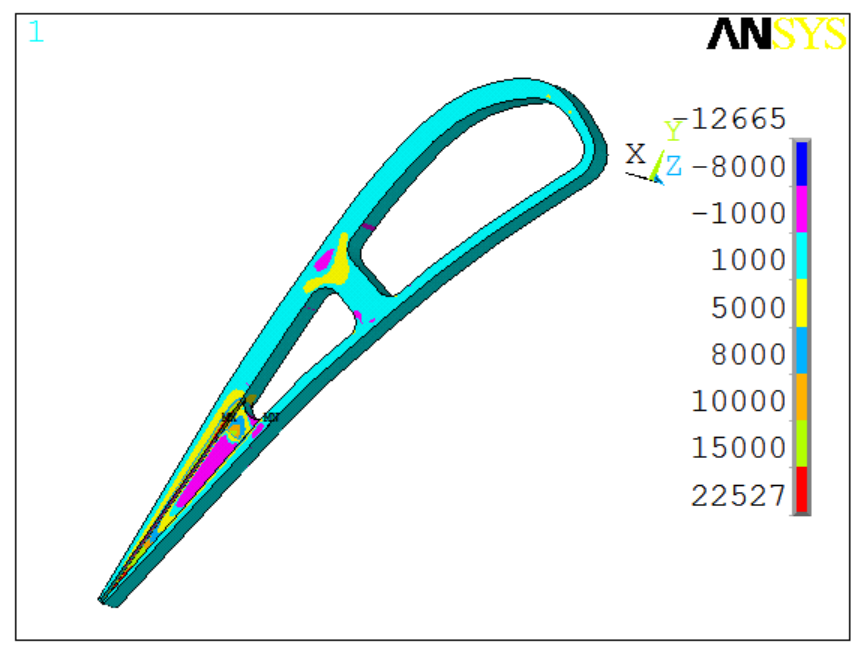

a) Through thickness stress, psi

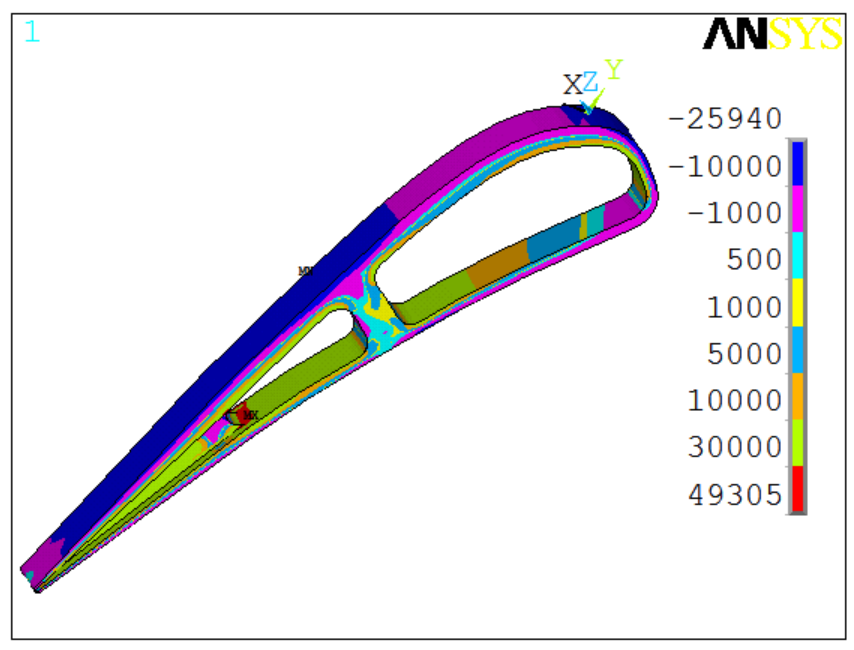

b) Hoop stress, psi

Fig. 25 Case 4 stresses - trailing edge ejection - temperature and pressure loads - differential wall thickness coefficient was halved from that used for the results shown in figure 25. It is possible to change the tube heat transfer coefficient without changing the tube flow rate. At a constant flow rate, the heat transfer coefficient is almost inversely proportional to the TEJ cross sectional area. Increasing the width of the TEJ would increase the area, without decreasing the CMC fraction in the spanwise direction.

Figure 27 shows stresses when a different TEJ configuration is used than the one shown in figure 25, but with the same TEJ tube heat transfer coefficient. Here the rectangular tube has a uniform cross section along its length. Also, the tube exits the vane on the pressure surface, rather than along the mean chamber line. While maximum through thickness stresses are still excessive, the area of high through thickness stresses was significantly reduced. Comparing figures 25a, 26a, and 27 a shows that through thickness stresses are very

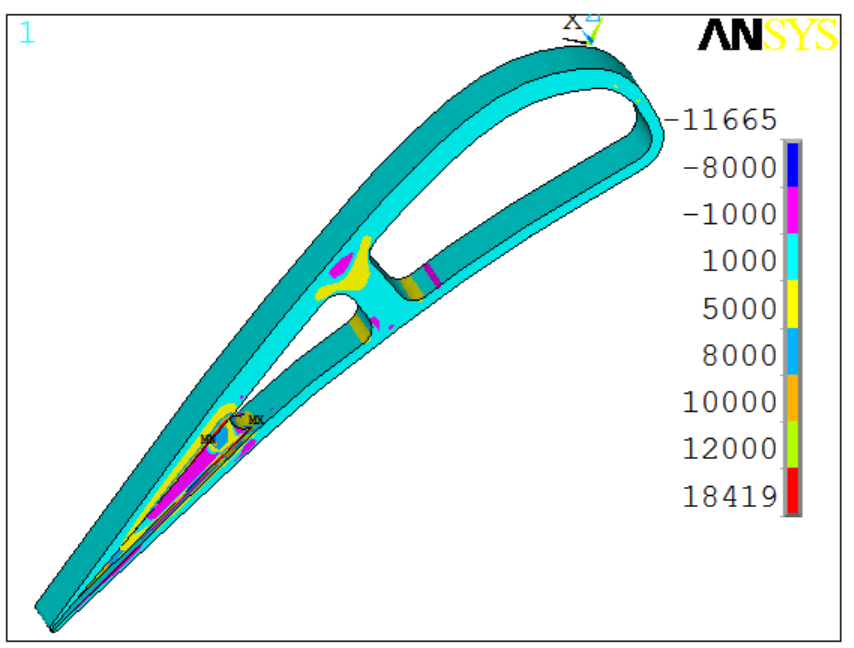

a) Through thickness stress, psi

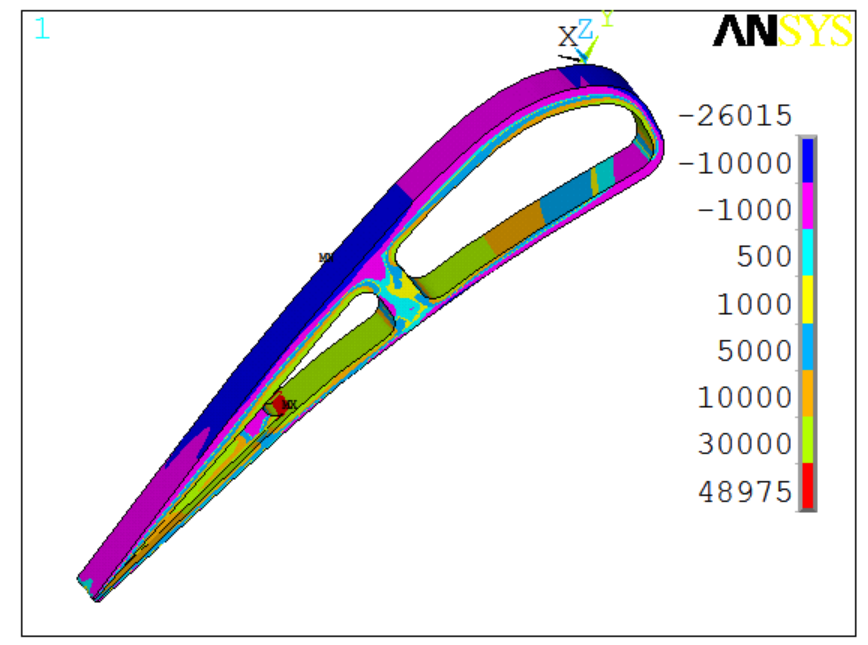

b) Hoop stress, psi

Fig. 26 Case $4 \mathrm{a}$ stresses - TEJ tube heat transfer coefficient halved-temperature \& pressure loads-differential wall thickness

sensitive to the arrangement of the TEJ tube. Maximum hoop stresses are nearly the same for the three TEJ configurations. However, the fraction of area experiencing high hoop stresses is dependent on the TEJ configuration.

\section{SUMMARY of MAXIMUM STRESS}

Table II summarized maximum tensile stresses for each case. In addition to the through thickness and hoop stresses, the peak spanwise stress in the midspan region is also shown. Because N24A is a two dimensional woven material, allowable stresses in the spanwise direction are the same as in the hoop direction. The stresses in this table show a relative ranking for maximum tensile stress. Previous figures showed that these maximum values are often highly localized. 
Table II. Maximum calculated stress, ksi,(MPa)

\begin{tabular}{|c|c|r|c|c|c|c|c|c|}
\hline Case & Load & Fig. & \multicolumn{2}{|c|}{ Through thickness } & \multicolumn{2}{|c|}{ Hoop } & \multicolumn{2}{|c|}{ Span } \\
\cline { 3 - 9 } & & & Value & Location & Value & Location & Value & Location \\
\hline 1 & Press & 9 & $4.62(31.9)$ & Fork & $31.4(217)$ & Fork & $11.1(76.5)$ & P-front \\
& Temp & 10 & $4.44(30.6)$ & L.E. & $20.4(141)$ & L.E. & $17.7(122)$ & Fork \\
\hline $1 \mathrm{a}$ & Temp & 12 & $6.91(47.6)$ & Fork & $31.1(214)$ & Fork & $28.5(197)$ & Fork \\
& Comb & 13 & $10.8(74.7)$ & Fork & $55.5(382)$ & Fork & $29.1(201)$ & Fork \\
\hline 2 & Press & 14 & $1.57(10.8)$ & Rib. & $17.0(117)$ & Fork & $8.05(55.5)$ & P-front \\
& Temp & 15 & $10.5(72.4)$ & Rib-P & $41.4(285)$ & Rib-P & $34.3(236)$ & Rib-P \\
& Comb & 16 & $10.6(73.1)$ & Rib-P & $45.6(314)$ & Rib-P & $36.9(254)$ & Rib-P \\
\hline 3 & Press & 17 & $2.40(16.5$ & Fork & $16.7(115)$ & Rib-S & $13.8(95.1)$ & P-front \\
& Temp & 19 & $8.52(58.7)$ & Rib-P & $38.2(263)$ & Rib-P & $31.1(214)$ & Rib-P \\
\hline $3 \mathrm{a}$ & Temp & 20 & $6.61(45.6)$ & Rib-P & $29.4(203)$ & Fork & $26.3(181)$ & P-aft \\
& Comb & 21 & $7.28(50.2)$ & Fork & $36.6(252)$ & Fork & $27.2(188)$ & P-aft \\
\hline 4 & Press & 22 & $9.04(62.3)$ & Fork & $24.4(168)$ & Fork & $16.5(114)$ & Fork \\
& Temp & 24 & $23.1(159)$ & T.E. & $35.4(244)$ & Fork & $74.4(513)$ & Fork \\
& Comb & 25 & $22.5(155)$ & Fork & $49.3(340)$ & Fork & $83.4(575)$ & Fork \\
\hline $4 \mathrm{a}$ & Comb & 26 & $18.4(127)$ & Fork & $49.0(338)$ & Fork & $74.2(512)$ & Fork \\
\hline 5 & Comb & 27 & $16.7(115)$ & Fork & $49.4(341)$ & Fork & $51.2(353)$ & Fork \\
\hline
\end{tabular}

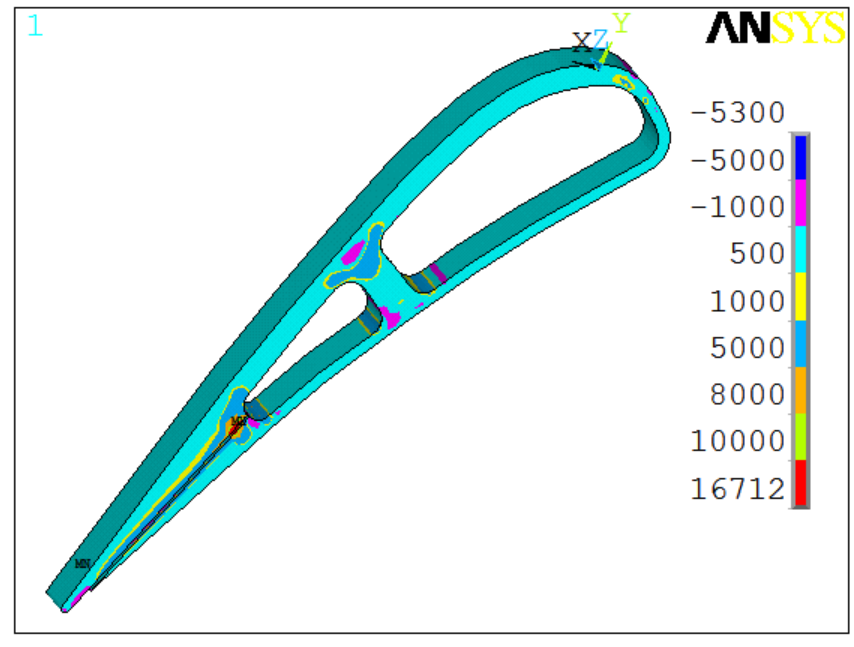

a) Through thickness stress, psi

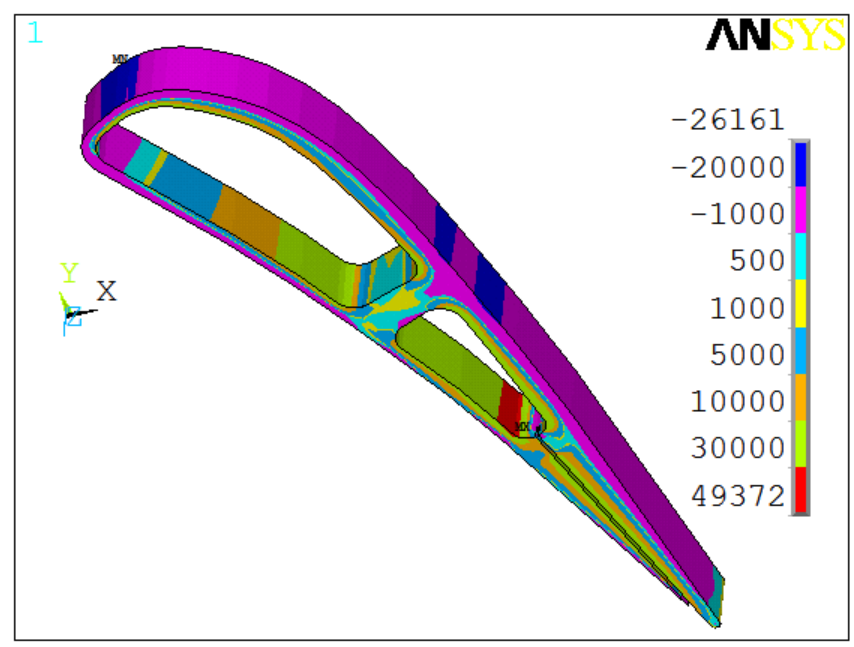

b) Hoop stress, psi

Fig. 27 Case 5 stresses for vane with pressure side TEJ temperature and pressure loads - differential wall thickness
They occur in regions where stresses change very rapidly. When creep or local yielding is accounted for, peak stresses may be lower than those shown in the table. Maximum hoop stresses in the fork region occur on the surface, where there are fibers. Maximum throuugh thickness stresses, when they are in the fork region, occur aft of the surface, where fibers may not be present. However, through thickness strengths are low because, being a $2 \mathrm{D}$ weave, the $\mathrm{N} 24 \mathrm{~A}$ material does not have fibers to resist loads in this direction.

Except for cases 4 and 5, which are for trailing edge ejection, the maximum stress in the spanwise direction is less than the maximum hoop stress. For the best TEJ case the spanwise stress, case 5 , the maximum spanwise stress is just slightly greater than the maximum hoop stress. Case 5 has a maximum through thickness stress nearly double that of the the best combined load case without TEJ.(case 3a). The maximum hoop stress is nearly $50 \%$ greater for case 5 than for case 3a. Case 5 required significantly less cool flow rates than did case 3a to satisfy temperature limits.

\section{CONCLUSIONS}

Significant benefits in terms of reduced NOx and improved cycle efficiency can be achieved by replacing conventional metal HPT vanes with higher temperature capable $\mathrm{CMC}$ vanes. To achieve these benefits, cooling schemes should resemble those used for current vanes, which use trailing edge ejection Unfortunately, TEJ increases maximum vane stresses.

Since many of the cases had maximum stresses greater than desired, further modifications of the vane geometry should be investigated. This work indicates the direction these modifications should take. Larger internal radii are expected to reduce peak fork and rib region stresses. Thicker walls at the rear of the trailing edge ejection tubes are likely to reduce peak stresses, but with an aerodynamic efficiency penalty. 
A rib connecting the pressure and suction surfaces of the vane is effective in reducing both through thickness and hoop stresses due to pressure loads. However, with a rib the maximum stresses due to thermal loads occurred in the rib region. These stresses were greater than the stresses in the fork region for the no rib cases.

Thermal stresses yielded higher maximum stress than pressure stresses. When pressure and thermal loads were simultaneously applied the maximum stress was generally less than the sum of the maximum pressure load stress and the maximum thermal load stress. However, the maximum combined load stress was greater than the maximum thermal stress alone.

Reducing the pressure surface wall thickness, reduced maximum through thickness and hoop stresses. Stresses on the pressure surface due only to pressure loads were acceptable, even though the wall thickness was halved from $2 \mathrm{~mm}$ (80 mil). Pressure load stresses in the fork region were reduced because of a larger radius at the rear of the aft impingement cavity. The thinner pressure surface resulted in lower thermal differences, and thus lower thermal stresses for this surface.

Insulating the rib connecting the pressure and suction surfaces, as opposed to cooling the rib with impingement air just like the rest of the vane's internal surface, reduced the maximum thermal stress.

Trailing edge ejection was found to be necessary to achieve the reduction in required coolant when using $\mathrm{CMC}$ vanes. Unfortunately, the trailing edge ejection holes increased maximum stresses substantially. Three trailing ejection configurations were analyzed. Reducing the heat transfer coefficient in the trailing edge ejection tube was beneficial. Using a constant area tube in place of a converging one was also beneficial, The straight tube resulted in lowering maximum through thickness and maximum spanwise stress in the midspan region by over $25 \%$. Unlike the other geometric configurations, cases with TEJ showed maximum spanwise stresses higher than the maximum hoop stress. However, the straight tube TEJ had nearly the same maximum hoop and spanwise stresses.

Acknowledgments. We would like to acknowledge the helpful discussions we had with Michael Vinup, Kin Poon, and Edward Zurmehly of Honeywell International Inc., and with Ramakrishna Bhatt, James DiCarlo and Jerry Lang of the NASA Glenn Research Center.

\section{REFERENCES}

1 Hartsel, J.E., 1972, "Prediction of Effects of Cooling Mass Transfer on the Blade Row Efficiency of Turbine Airfoils," AIAA paper 72-11.

2 Verrilli, M., Calamino,, A., Robinson, R.C., and Thomas, D.J.,2004, "Ceramic Matrix Composite Vane Subelement Testing in a Gas Turbine Environment, ASME Paper GT2004-53970.
3 Brewer, D.N., Verrilli, M., and Calomino, A., 2006, "Ceramic Matrix Composite Vane Subelement Burst Testing", ASME paper GT2006-90883.

4 Watanabe, K.-I., Suzumura, N., Nakamura, T., Murata, H., Araki, T., and Natsumura, T., 2008, "Development of CMC Vane for Gas Turbine Engine", Ceramic Engineering and Science Proceedings, Volume 24, Issue 4, (eds W. M. Kriven and H.-T. Lin), John Wiley \& Sons, Inc., Hoboken, NJ, USA. doi: 10.1002/9780470294826.ch87

5 Nakamura, T., Murata, H., Takahashi, A., and Okita, Y., 2010, "Development of a CMC Turbine Vane", in Proceedings of the $7^{\text {th }}$ International Conference on High Temperature CMCs(HT CMC7), pp. 559-565.

6 Vedula, V., Shi, J., Jarmon, D., Ochs, S., Oni, L., Lawton, T., Green, K., Prill, L., Schaff, J., and Linsey, G., 2005, "Ceramic Matrix Composite Vanes for Gas Turbine Engines, ASME Paper GT2005-68229

7 Marshall, D.B., and Cox, B.N., 2008, "Integral Textile Ceramic Structures," Annual Review of Materials Research, Vol. 38, pp. 425-443.

8 Halila, E.E., Lenahan, D.T., and Thomas, T.T., 1982, "High Pressure Turbine Test Hardware Detailed Design Report", NASA CR-167955, General Electric Company report R81AEG284

9 Mital, S.K., Bednarcyk, B.A., Arnold S.A., and Lang, J., 2009, "Modeling of Melt-Infiltrated $\mathrm{SiC} / \mathrm{SiC}$ Composite Properties," NASA TM-2009-215806.

10 DiCarlo, J.A,, Yun, H.-M., Morsher, G.N., and Bhatt, R.T., 2004, "SiC/SiC Composites for $1200{ }^{\circ} \mathrm{C}$ and Above," NASA TM-2004-213048

11 Lee, K.N., Fox, D.S., Eldridge, J.I., Zhu, D., Robinson, R.C., Bansal, N.P., and Miller, R.A., 2002, "Upper Temperature Limit of Environmental Barrier Coatings Based on Mullite and BSAS," NASA TM-2002-211372

12 www.specialmetals.com

13 Reiss, H., and Bolcs, A., 1999, "Experimental Study of Showerhead Cooling on a Cylinder Comparing Several Configurations Using Cylindrical and Shaped Holes," ASME paper 99-GT-123.

14 Boyle, R.J., and Ameri, A.A., 2010, "A Correlation Approach to Predicting Film Cooled Turbine Vane Heat Transfer," ASME paper GT2010-23597.

15 Tacina, R., Wey, C., Laing, P., and Mansour, A., 2002, "A Low NOx Lean-Direct Injection, Multipoint Integrated Module Combustor Concept for Advanced Aircraft Gas Turbines," NASA TM-2002-211347, Presented at the Conference on Technologies and Combustion for a Clean Environment, Oporto, Portugal, July 2001.

16 Tacina, R.R., Wey, C., and Choi, K.J., 2001, "Flame Tube NOx Emissions Using a Lean-Direct-Wall-Injection Concept," AIAA paper 2001-3271(NASA TM-2001-211105). 17 Anon., 2007, "Performance Prediction and Simulation of Gas Turbine Engine Operation for Aircraft, Marine, Vehicular, and Power Generation," NATO Report RTO-TRATV-036

18 Anon., 2009, "ANSYS Mechanical APDL, Release 12.1," 19 Kaufman, A., 1969, "Steady-State Stress Relaxation Analysis of Turbine Blade Cooling Designs," NASA TND-5282. 